\title{
IUPAC Commission on the Nomenclature of Organic Chemistry and IUPAC-IUB Commission on Biochemical Nomenclature Revised Tentative Rules for Nomenclature of Steroids* $+\ddagger$
}

\section{CONTENTS}

Rule

$\begin{array}{llllll} & \text { Introduction } & \ldots & \ldots & \ldots & \ldots \\ \text { 2S-1 } & \text { General } & \ldots & \ldots & \ldots & \ldots\end{array}$

2S-2 Fundamental carbocycles ... ...

2S-3 Penta- and hexa-cyclic modifications

2S-4 Derivatives ... $\quad \ldots \quad \ldots \quad \ldots$

2S-5 Stereochemical modifications ...

2S-6 Shortening of side chains and elimina-

tion of methyl groups $\quad \ldots \quad \ldots$

2S-7 Ring contraction or expansion ...

$2 S-8$ Ring fission $\ldots \quad \ldots . \quad \ldots \quad \ldots$

2S-9 Modification by bond migration (abeo system) $\quad \ldots \quad \ldots \quad \ldots \quad \ldots$

2S-10 Hetero modifications... $\quad \ldots \quad \ldots$

2S-11 Steroid alkaloids $\quad \ldots \quad \ldots \quad \ldots$

Appendix : Guide lines for steroids containing additional rings $\quad \ldots \quad \ldots \quad \ldots$

\section{INTRODUCTION}

The rules of steroid nomenclature originate from a discussion held at the Ciba Foundation in London, England, in 1950 between the representatives of many schools. These were published in Chem. \& Ind. (1951), pp. SN 1-11, and also in French and

* These Rules shall be known as the IUPAC-IUB 1967 Revised Tentative Rules for Steroid Nomenclature.

+ These Rules are issued by the IUPAC Commission on the Nomenclature of Organic Chemistry [P. E. Verkade (Chairman), L. C. Cross, G. M. Dyson, K. L. Loening, N. Lozac'h, H. S. Nutting, J. Rigaudy, S. Veibel; associate members, R. S. Cahn, S. P. Klesney; observers, K. A. Jensen, W. Klyne], and by the IUPAC-IUB Commission of Biochemical Nomenclature [O. Hoffmann-Ostenhof (Chairman), A. E. Braunstein, W. E. Cohn, J. S. Fruton, P. Karlson, B. Keil, W. Klyne, C. Liébecq, E. C. Slater, E. C. Webb; corresponding member, N. Tamiya; observer, S. Veibel].

$\mp$ Comments on and suggestions for future revisions of these Tentative Rules should be sent to: Professor P. E. Verkade, Ary Schefferstraat, 217, 's-Gravenhage, The Netherlands, or Professor O. Hoffmann-Ostenhof, Biochemische Abteilung, Organisch-Chemisches Institut der Universität Wien, Währingerstrasse 38, 1090 Vienna, Austria, or to any member of the Commissions named above. Reprints of these Revised Tentative Rules may be obtained from the NAS-NRC Office of Biochemical Nomenclature (Dr Waldo E. Cohn, Director), Biology Division, Oak Ridge National Laboratory, Oak Ridge, Tenn. 37830, U.S.A.
German. They were subsequently taken over by the International Union of Pure and Applied Chemistry and published in an official form in the Comptes rendus of the Zurich meeting in 1952 [also IUPAC Nomenclature of Organic Chemistry, Sections $A$ and $B, 1957$, 1st ed. 1958; 2nd ed. 1966, pp. 71-82. London: Butterworths; and numerous reprints and translations, including $J$. Amer. chem. Soc. (1960) 82, 5577-5581].

In 1960 a group of specialists under the chairmanship of Professor T. Reichstein, including representatives of the IUPAC Commissions of the Nomenclature of Organic Chemistry and of Biochemical Nomenclature, met in Basle, Switzerland, for discussions of amendments and additions to the Rules. Agreement was not reached on all the points discussed, and the results of this meeting were therefore published in discussion form in the IUPAC Information Bulletin, no. 11. They have generally been referred to as the 'Basle Proposals'.

Since then, many points in the Basle proposals have become almost universally accepted in the literature. In 1965 the two International Commissions concerned, namely the IUPAC Commission of the Nomenclature of Organic Chemistry and the Commission on Biochemical Nomenclature (now jointly responsible to IUPAC and IUB), decided that the time had come for as many as possible of the Basle Proposals to be formulated as rules.

The present Rules include: all the original Rules, mostly renumbered (with additions and amendments arising from the Basle Proposals or from current practice in the literature); and most of the Basle Proposals, namely those that have been generally accepted. Further, adoption of the sequence-rule procedure [R. S. Cahn, C. K. Ingold \& V. Prelog, Angew. Chem. int. Ed. (1966). 5, 385 (in English); Angew. Chem. (1966). 78, 413 (in German); for a partial simplified account see R. S. Cahn, $J$. chem. Educ. (1964). 41, 116] for general stereochemical descriptions in much of the chemical literature has permitted its introduction now also for some sections of steroid nomenclature that were previously in dispute or intractable. Decisions on a few of the Basle Proposals have, however, been postponed; it is hoped that further experience will indicate the most appropriate ways of dealing with them. 


\section{General application}

Although these Rules are called 'Rules for Nomenclature of Steroids', many of the principles therein have become almost universally accepted also in diterpene and triterpene chemistry; also to some extent for sesquiterpenes and for several groups of alkaloids. It is suggested that the same principles may be applied to a number of other specialized groups of natural products, perhaps without the need for further official rules, so long as the basic ideas are followed. These principles include: (i) clear definition of stem names and the stereochemistry implied in them; (ii) systematic application of the rules of general organic chemical nomenclature, with modifications where special considerations make this necessary ; (iii) application of the methods of skeletal modification given in these Rules, viz. the use of homo and nor for, respectively, stepwise expansion and contraction of ring systems; the use of seco for reductive fission of ring systems; and the use of abeo for formal bond migrations (this flexible concept was first proposed by Professor D. H. R. Barton at an informal meeting of terpene chemists convened by the Chemical Society in London, England).

\section{RULES}

Rules are numbered $2 \mathrm{~S}-1,2 \mathrm{~S}-2,2 \mathrm{~S}-3$ etc., the first ' 2 ' denoting that this is the second or revised set of rules. The numbers of the corresponding previous rules, where they exist, are included for comparisons.

\section{General}

Rule 2S-1 (expanded from Rules S-1 and S-2).

1.1. Steroids are numbered and rings are lettered as in formula (1). If one of the two methyl groups attached to C-25 is substituted it is assigned the lower number (26); if both are substituted, that carrying the substituent cited first in the alphabetical order or order of complexity is assigned the lower number [cf. IUPAC Rule C-15.11(e); IUPAC Nomenclature of Organic Chemistry, Section C, 1965, London: Butterworths; also Pure appl. Chem. (1965). 11, nos. 1 and 2]. For trimethyl steroids see Rule 2S-2.3, Note b.

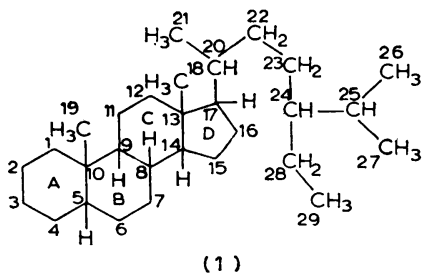

1.2. If one or more of the carbon atoms shown in (1) is not present and a steroid name is used, the numbering of the remainder is undisturbed.

1.3. For a steroid the name, including stereochemical affixes, and its structural formula (see Rule 2S-1.4), denote the absolute configuration at each asymmetric centre (see also Rule 2S-1.5). When the configuration at one or more centres is not known, this is indicated by Greek letter(s) $\xi$ (xi) prefixed by the appropriate numeral(s).

1.4. When the rings of a steroid are denoted as projections on to the plane of the paper, the formula is normally to be oriented as in (2). An atom or

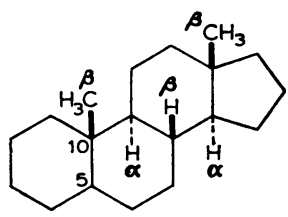

(2)

group attached to a ring depicted as in the orientation (2) is termed $\alpha$ (alpha) if it lies below the plane of the paper or $\beta$ (beta) if it lies above the plane of the paper. In formulae, bonds to atoms or groups lying below the plane of the paper are shown as broken (---) lines, and bonds to atoms or groups lying above the plane of the paper are shown as solid lines (preferably thickened $\longrightarrow$ ). Bonds to atoms or groups whose configuration is not known or is unspecified are denoted by wavy lines ( $m$ ).

Notes: (1) Projections of steroid formulae should not be oriented as in formula (3), (4) or (5) unless circumstances make it obligatory.

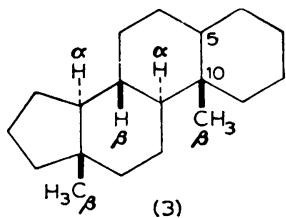

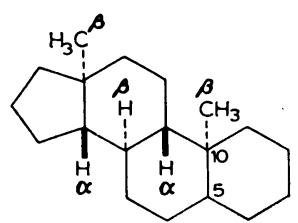

(4)

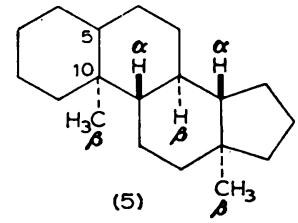

(5)
(2) With the preferred orientation (2), and with (3), $\alpha$-bonds appear as broken lines and $\beta$-bonds as solid (thickened) lines. The reverse is true for (4) and (5). Wavy lines denote $\xi$-bonds for all orientations of the formula.

(3) A perspective representation of the stereochemistry of formula (2) as in (2a) or (2b) may also be used. 


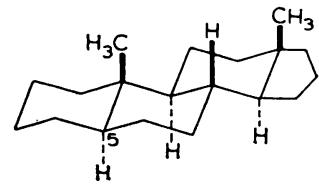

(2 a)

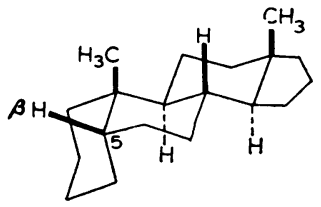

(2b).
A $5 \alpha$-steroid

A $5 \beta$-steroid

(For the significance of the prefixes $5 \alpha$ - and $5 \beta$ - see Rule 2S-1.5.)

When steroid formulae are drawn in this way, bonds pointing upwards are, by convention, drawn bold and bonds pointing downwards are drawn broken; these representations correspond to the $\beta$ and $\alpha$-bonds of projection formulae such as (2) and do not conform to the general practice that bold and broken lines denote bonds projecting respectively above and below the plane of the paper. Note, however, that the general practice is followed with chair and boat forms of spirostans (see Rule 2S-3.3).

(4) All hydrogen atoms and methyl groups attached at ring-junction positions must always be inserted as $\mathrm{H}$ and $\mathrm{CH}_{3}$ respectively ( $\mathrm{Me}$ may be used in place of $\mathrm{CH}_{3}$ if editorial conventions require it). The practice, sometimes followed, of denoting methyl groups by bonds without lettering is liable to cause confusion and should be abandoned. This is essential in view of customs in other fields and applies also to other groups of compounds such as cyclic terpenes and alkaloids for which steroid conventions are commonly used.

1.5. Unless implied or stated to the contrary (see Rules 2S-3, 2S-4.3, 2S-5 and 2S-11), use of a steroid name implies that atoms or groups attached at the ring-junction positions $8,9,10,13$ and 14 are oriented as shown in formula (2) (i.e. $8 \beta, 9 \alpha, 10 \beta$, $13 \beta, 14 \alpha$ ), and a carbon chain attached at position 17 is assumed to be $\beta$-oriented (see Notes below). The configuration of hydrogen (or a substituent) at the ring-junction position 5 is always to be designated by adding $\alpha, \beta$ or $\xi$ after the numeral 5 , this numeral and letter being placed immediately before the stem name. The configuration of substituents attached at other centres of asymmetry in the tetracyclic system $\mathbf{A}-\mathbf{D}$ is stated by adding $\alpha, \beta$ or $\xi$ after the respective numerals denoting their position.

Notes: For the purpose of this Rule a carboxyl group at position 17 is not considered to constitute a carbon 'chain' (for the nomenclature used see Rule 2S-4.3). For penta- and hexa-cyclic derivatives see Rule 2S-3, and for stereochemical modifications see Rule 2S-5.

1.6. When the configuration at position 20 in the side chain of a pregnane derivative (for the name 'pregnane' see Rule 2S-2.3) is as depicted in the projection formula (6) (i.e. a Fischer projection but with the highest number at the top), substituents shown to the right of C-20 are termed $\alpha$ and those to the left are termed $\beta$.

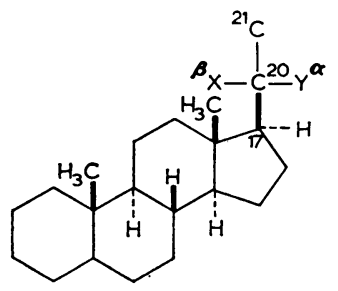

(6)

Examples:

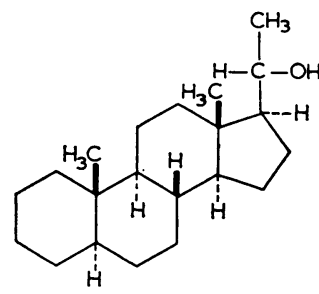

(7)

$5 \alpha$-Pregnan-20 $\alpha$-ol*

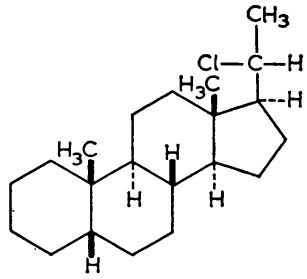

(8)
* For the name 'pregnane' see Rule 2S-2.3.

Notes: (1) The $20 \alpha / 20 \beta$-nomenclature is continued because of long tradition. When a longer side chain is present at C-17 the sequence-rule procedure (see references cited in the Introduction) is more generally convenient (see Rule 2S-1.7) and it may also be used to designate stereochemistry at C-20 in pregnanes, being particularly useful for 20-substituents that may cyclize with a substituent at another position [ө.g. carboxylic acids as in example (12)]. For 20-hydroxy-, 20-alkoxy-, 20-acyloxy-, 20-amino- and 20-halogeno- derivatives of pregnane without a substituent on C-17 or $\mathrm{C}-21,20 \alpha$ - is equivalent to $(20 S)$-, and $20 \beta$ - to $(20 R)$-; however, these equivalences are sometimes reversed when additional substituents are present, e.g. on C-17 or C-21, and in such cases the references cited in the Introduction should be consulted.

(2) When stereochemistry at C-20 is denoted by a Fischer-type projection, as in (6)-(11) or for cardenolides as (37) or bufanolides as (43), the 17,20 -bond is preferably denoted by an ordinary line; the stereochemistry at C-17 is then adequately denoted by a thick or a broken bond to the $\mathbf{H}$ or to the other substituent (e.g. $\mathrm{OH}$ ) at position 17. In such formulae, representing the 17,20-bond by a thick or a broken line cannot be correct for both C-17 and C-20; this has, however, frequently been done, then involving the additional convention that the way in which this bond is written is neglected when considering the stereochemistry at C-20.

1.7. The stereochemistry at C-20 and other positions in steroid side chains longer than ethyl is 
<smiles>CCC(C)(O)[C+](C)(C)C</smiles>

(9)

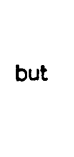<smiles>CC(C)[C@H](O)CO</smiles>

(10)

$20 \alpha, 2$ I-diol $(20 R)$

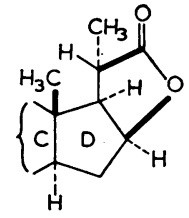

(12)<smiles>OCCO[GeH3]</smiles><smiles>CC(C)(O)C(O)CO</smiles>

(11)

(20S)-16 $\beta$-Hydroxypregnane20-carboxylic acid lactọne (三 20 $\alpha$ )

described by the sequence-rule procedure (see references cited in the Introduction).

Examples:

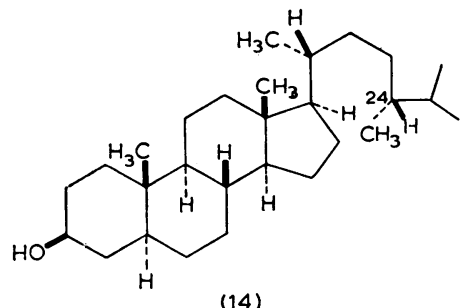

(24R)-24-Methyl-5 $\alpha$-cholestan- $3 \beta$-ol* (formerly $24 \alpha$-methyl)

(trivial name: campestanol)

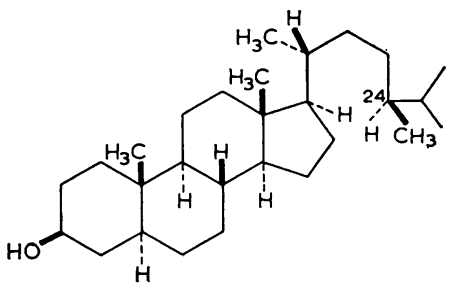

(15)

(24S)-24-Methyl-5 $\alpha$-cholestan-3 $\beta$-ol* (formerly $24 \beta$-methyl)

(trivial name: ergostanol)

* For the name 'cholestane' see Rule S2-2.3. These systematic names are preferred to the trivial names given below them.

Notes: (1) The sequence-rule procedure is also used when the side chain is cyclized (see Rules 2S-3.3 and 2S-3.4).

(2) The backbone of a 17-side chain is best denoted as in the plane of the paper (lines of ordinary thickness), the 17,20-bond being similarly denoted.

Except for pregnane derivatives, stereochemistry due to substituents on the chain is then indicated by the customary thick or broken lines denoting bonds that project, respectively, above and below the plane of the paper.

\section{Fundamental carbocycles}

Rule 2S-2 (expanded from Rules S-3.1 to S-3.5).

2.1. The parent tetracyclic hydrocarbon without methyl groups at C-10 and C-13 and without a side chain at C-17 is named 'gonane'.

2.2. The hydrocarbon with a methyl group at C-13 but without a methyl group at C-10 and without a side chain at C-17 is named 'estrane'.

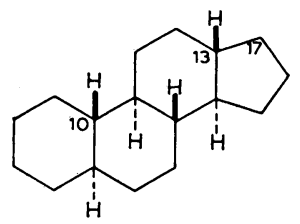

(16) $5 \alpha$-Gonane<smiles>C[C@]12CCC[C@H]1[C@H]1CC[C@H]3CCCC[C@H]3[C@H]1CC2</smiles>

(18)

$5 \alpha$-Estrane

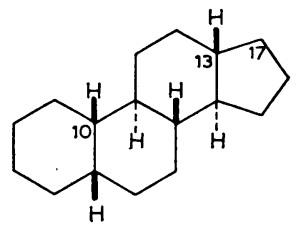

(17)

$5 \beta$-Gonane<smiles>C[C@]12CCC[C@H]1[C@H]1CC[C@H]3CCCC[C@H]3[C@H]1CC2</smiles>

(19)

$5 \beta$-Estrane
Note: Names of compounds having a methyl group attached to $\mathrm{C}-10$ and a hydrogen atom attached to C-13 are to be based on 18-norandrostane (see Rules 2S-2.3 and 2S-7.1) and not on 10-methylgonane.

2.3. The following names are used for the hydro- 
carbons (20) and (21) with methyl groups at both C-10 and C-13.

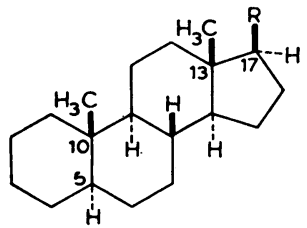

(20)

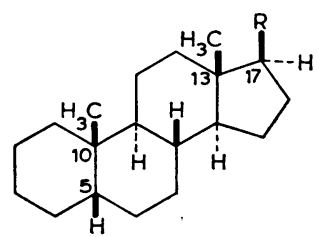

(21)

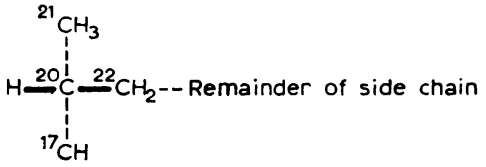

(26)

(c) Tetracyclic triterpenoids may be regarded as trimethyl steroids, the three additional methyl groups being numbered 30 (attached to $\mathrm{C}-4$ with
$\mathbf{R}$

$\mathbf{H}$

$\mathrm{C}_{2} \mathrm{H}_{5}$

* $\mathrm{CH}\left(\mathrm{CH}_{3}\right) \mathrm{CH}_{2} \mathrm{CH}_{2} \mathrm{CH}_{3}$

* $\mathrm{CH}\left(\mathrm{CH}_{3}\right) \mathrm{CH}_{2} \mathrm{CH}_{2} \mathrm{CH}_{2} \mathrm{CH}\left(\mathrm{CH}_{3}\right)_{2}$

$24 \dagger$

* $\mathrm{CH}\left(\mathrm{CH}_{3}\right) \mathrm{CH}_{2} \mathrm{CH}_{2} \mathrm{CH}\left(\mathrm{CH}_{3}\right) \mathrm{CH}\left(\mathrm{CH}_{3}\right)_{2}$

24 t

* $\mathrm{CH}\left(\mathrm{CH}_{3}\right) \mathrm{CH}_{2} \mathrm{CH}_{2} \mathrm{CH}\left(\mathrm{C}_{2} \mathrm{H}_{5}\right) \mathrm{CH}\left(\mathrm{CH}_{3}\right)_{2}$
(20) $5 \alpha$-Series

$5 \alpha$-Androstane

$5 \alpha$-Pregnane (not allopregnane)

$5 \alpha$-Cholane (not allocholane)

$5 \alpha$-Cholestane

$5 \alpha$-Ergostane

$5 \alpha$-Stigmastane

*20R-Configuration.

$\dagger$ 24S-Configuration.

$\ddagger 24 R$-Configuration.
(21) $5 \beta$-Series

$5 \beta$-Androstane (not testane)

$5 \beta$-Pregnane

$5 \beta$-Cholane

$5 \beta$-Cholestane (not coprostane)

$5 \beta$-Ergostane

$5 \beta$-Stigmastane
Notes: (a) Unsaturation and substituents are denoted in the names of steroids by the usual methods of organic chemistry (cf. Rule 2S-4). Examples (22)-(25) illustrate some simple cases.<smiles>CC12CCCC1C1CCc3ccccc3C1CC2</smiles>

(22)<smiles>CC12CCCC1c1ccc3ccccc3c1CC2</smiles>

(23)
I,3,5(10)-Estratriene

r,3,5(I0),6,8-Estrapentaene<smiles>CC12CCC3C(CCC4C3CCC3CCC=C[C@@]34C)CC1C2</smiles>

(24)

$5 \alpha$-Androst-I-en-I6 6 -ol<smiles>C#C[C@H]1CC[C@H]2C3=C(C=C[C@@]12C)[C@]1(C)CC[C@@H](O)C[C@H]1C=C3</smiles>

(25)

$5 \beta, 13 \xi, 14 \xi-P r e g n a-6,8,1 \mathrm{I}-$ trien-20-yn-3 $\alpha$-ol

(b) The names 'cholane', ' cholestane', 'ergostane' and 'stigmastane' imply the configuration at C-20 shown in partial formula (26); this is $(20 R)$ except for some derivatives containing additional substituents (cf. Notes to Rule 2S-1.6). $\alpha$-configuration), 31 (attached to C-4 with $\beta$ configuration) and 32 (attached to C-14); for example, $5 \alpha$-lanostane $(27)$ is $4,4,14 \alpha$-trimethyl$5 \alpha$-cholestane, the former name implying $14 \alpha, 20 R$ configuration. Trivial names are common in this series of compounds, and some are illustrated in examples (27)-(31).

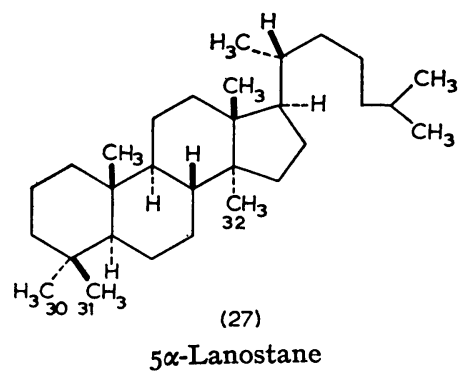<smiles>CC(C)CCCC(C)(C)[C@H]1CCC2(C)[C@H]3CCC4(C)C(C)(C)CCC[C@]4(C)[C@H]3CCC12C</smiles>

(28)

$5 \alpha$-Tirucallane $5 \alpha, \mathrm{I} 3 \alpha, \mathrm{I} 4 \beta, \mathrm{I} 7 \alpha, 20 S$-Lanostane 
<smiles>CC(C)CCC[C@H](C)[C@H]1CC[C@]2(C)[C@H]3CC[C@H]4C(C)(C)CCC[C@]4(C)[C@H]3CC[C@]12C</smiles>

(29)

$5 \alpha$-Euphane

$5 \alpha, 1_{3} \alpha, 1_{4} \beta$, I $7 \alpha$-Lanostane (20R implied in the name)

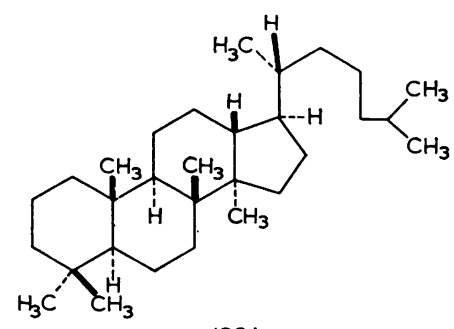

(30)

$5 \alpha$-Dammarane

8-Methyl-r 8-nor-5 $\alpha$-lanostane (all configurations except $5 \alpha$ are implied in the name)<smiles>CC(C)CCC[C@H](C)C1CCC2(C)[C@H]1CC[C@]1(C)[C@@H]2CC[C@]2(C)[C@@H]1CCCC2(C)C</smiles>

(31)

$5 \alpha$-Cucurbitane I9 $(10 \rightarrow 9 \beta)-a b e 0-5 \alpha$-Lanostane (for the abeo nomenclature see Rule $2 \mathrm{~S}-9$ )

2.4. When an additional ring is formed by means of a direct link between any two carbon atoms of the steroid ring system or the attached side chain, the name of the steroid is prefixed by 'cyclo'; this prefix is preceded by the numbers of the positions joined by the new bond and the Greek letter $(\alpha, \beta$ or $\xi$ ) denoting the configuration of the new bond, unless that designation is already implicit in the name.

Examples:

\section{Penta- and hexa-cyclic modifications}

Rule 2S-3 (amended versions of Rules S-3.6 to S-3.9).

3.1. (a) The name 'cardanolide' is used for the fully saturated system (37) of digitaloid lactones whose configuration is as illustrated [the configuration at position 20 is shown as a Fischer-type projection (this method of drawing is customary for the steroids; since the highest-numbered atom is at<smiles></smiles>

(32)<smiles>[2H]C1CCC2C3CC4(C)C(O)CCCC4(C)C3CCC12C</smiles>

(33)

$\mathrm{R}=\mathrm{CH}\left(\mathrm{CH}_{3}\right) \mathrm{CH}_{2} \mathrm{CH}_{2} \mathrm{CH}_{2} \mathrm{CH}\left(\mathrm{CH}_{3}\right)_{2}$

$3 \alpha, 5$-Cyclo- $5 \alpha$-cholestan- $6 \beta$-ol<smiles>CC12CCCC1C1CCC3CCCCC34CC4(C)C12</smiles>

(34)
5,7 $\alpha$-Cyclo- $5 \alpha$-cholestan- $4 \alpha-01$<smiles>CC12CCCC1C1CCC3CCCCC34CCC1(C)C24</smiles>

(35)

I $\beta$, I9-Cyclo- $5 \alpha$-androstane 


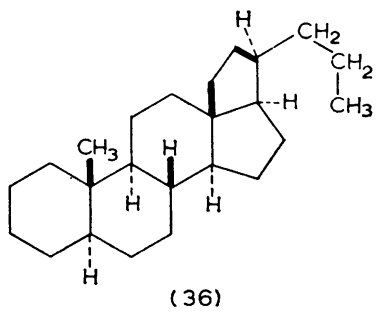

(20R)-I 8,2 I-Cyclo- $5 \alpha$-cholane

the top, the usual Fischer projection has been rotated in the plane of the paper through $180^{\circ}$ ) and is the same as that in cholesterol, i.e. 20R]. Notwithstanding Rule 2S-1.5, the configuration at position 14 must always be stated as an affix to the names of these compounds.

(b) Names such as '20(22)-cardenolide' are used for the naturally occurring unsaturated lactones of this type.

(c) The names ' 14,21 -' and '16,21-epoxycardanolide' are used for the compounds containing a 14,21- or a 16,21-oxygen bridge respectively.

Note: Statement of the configuration at C-14 for all cardanolides is a change from the earlier steroid Rules and is in line with current practice.

Examples:

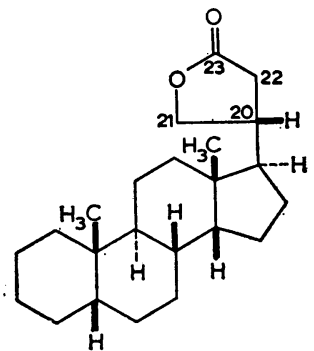

(37)

${ }_{5} \beta$, г $4 \beta$-Cardanolide

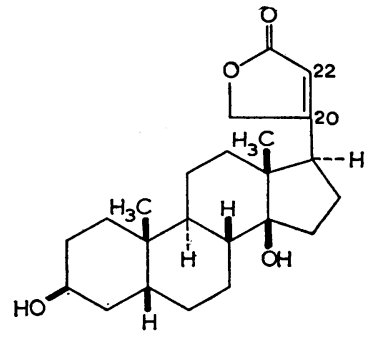

(38)

3 $\beta$, I4-Dihydroxy- $\beta$, I $4 \beta$-card-2o(22)-enolide (= digitoxigenin*)

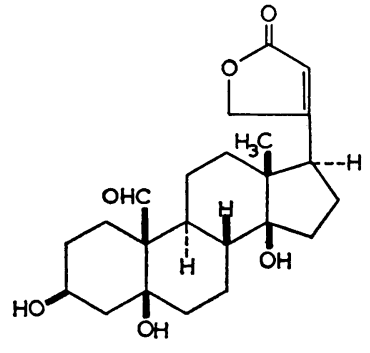

(39)

$3 \beta, 5, \mathrm{r} 4$-Trihydroxy-19-oxo- $5 \beta, \mathrm{r} 4 \beta$-card20(22)-enolide ( $=$ strophanthidin*)<smiles>C[C@]12CC[C@H]3[C@@H](CC[C@]4(O)C[C@@H](O)CC[C@]34C)[C@@H]1CC[C@H]2C1=CC(=O)OC1</smiles>

(40)

$3 \beta, 5, \mathrm{r} 4$-Trihydroxy-19-0xo- $5 \beta, \mathrm{I} 4 \beta, \mathrm{I} 7 \alpha$-card20(22)-enolide ( $=$ I $7 \alpha$-strophanthidin*) (also, allostrophanthidin + )

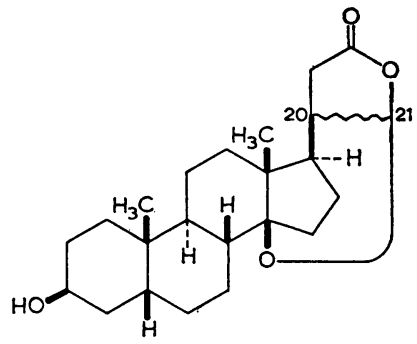

(41)

$3 \beta$-Hydroxy-r $4,21 \xi$-epoxy- $5 \beta, 14 \beta, 20 \xi-$ cardanolide ( $=$ isodigitoxigenin $\dagger$ )

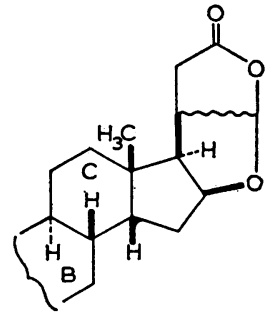

(42)

A $16 \beta, 21 \xi$-epoxy-I $4 \beta, 20 \xi$-cardanolide

* Denotes a trivial name; the systematic name is preferred. $\dagger$ Denotes a previous trivial name now considered unacceptable. 
3.2. The name 'bufanolide' is used for the fully saturated system (43) of the squill-toad poison group of lactones, with the configuration at position 20 shown [this configuration is drawn as a Fischertype projection (see Note to Rule 2S-3.1(a)) and is the same as in cholesterol, i.e. 20R]. Notwithstanding Rule 2S-1.5, the configuration at position 14 must always be stated as an affix to the names of these compounds. Unsaturated derivatives are named by replacing the suffix -anolide by -enolide, -adienolide etc.; thus the name ' 20,22 -bufadienolide' is used for the naturally occurring doubly unsaturated lactones.

Note: Statement of the configuration at C-14 for all bufanolides is a change from the earlier steroid Rules and is in line with current practice.

Examples:

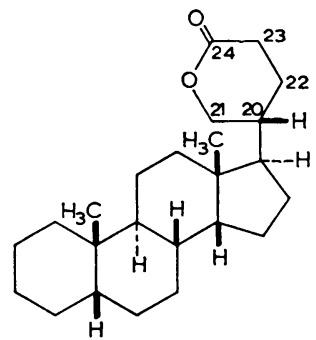

(43)

$5 \beta$, I4 $\beta$-Bufanolide

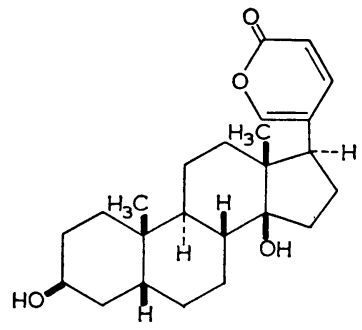

(44)

$3 \beta, \mathrm{r} 4$-Dihydroxy-5 $\beta, \mathrm{r} 4 \beta$-bufa-20,22-dienolide (= bufalin*)

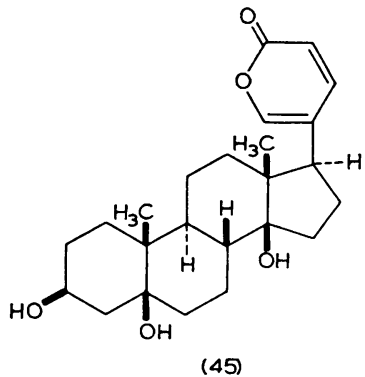

$3 \beta, 5, \mathrm{I} 4$-Trihydroxy- $5 \beta, \mathrm{I} 4 \beta$-bufa-20,22dienolide ( $=$ telecinobufagin $*$ )

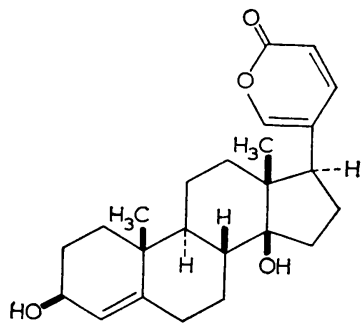

(46)

$3 \beta$, I 4-Dihydroxy-I $4 \beta$-bufa-4,20, 22-trienolide $(=$ scillarenin $*)$

* Denotes a trivial name; the systematic name is preferred.

3.3. The name 'spirostan' is used for the compound of structure (47) (this is a 16,22:22,26 diepoxycholestane); this name specifies the configurations shown for all the asymmetric centres except positions 5 and 25 . A prefix $5 \alpha$ - or $5 \beta$ - is added in the usual way (see Rule 2S-1.5). Configurations at C-16 and C-17, if different from those shown in formula (47), are designated as $16 \beta(\mathrm{H})$ and $17 \beta(\mathrm{H})$. Configurations at $\mathrm{C}-20$ and $\mathrm{C}-22$, if different from those shown in formula (47), are designated by the sequence-rule procedure (see references cited in the Introduction) or, if unknown, by $\xi$. Steric relations of substituents at C-23, C-24, C-25 or C-26 are in all cases designated by the sequence-rule procedure or, if unknown, by $\xi$.

Examples:
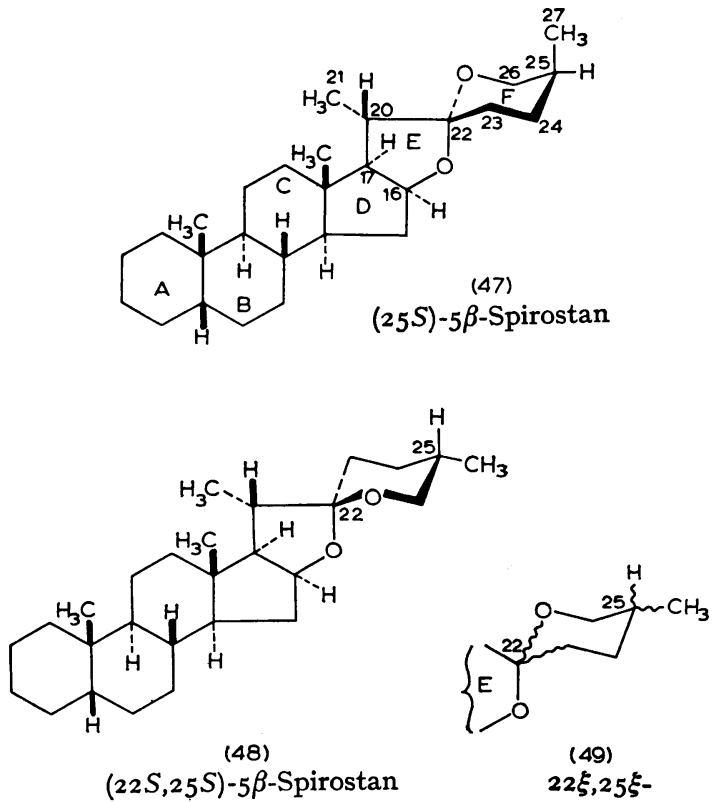


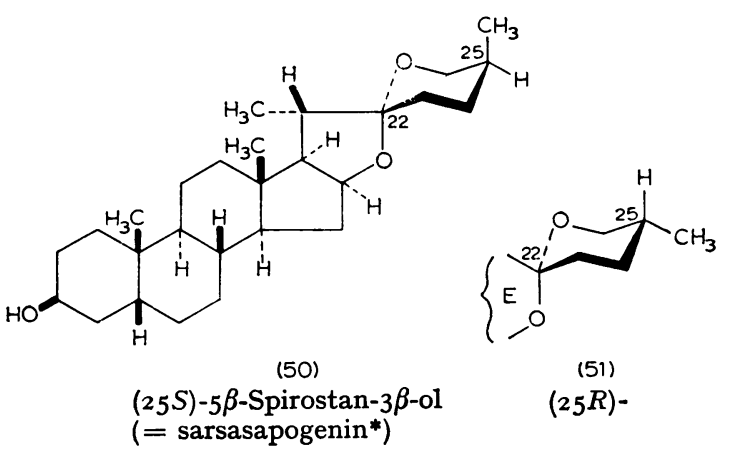

* Denotes a trivial name; the systematic name is preferred.

Notes: Several other methods have been used in the past for designating stereochemistry at C-22 and C-25 in the spirostans and related series; all involve serious difficulties (cf. the Basle Proposals, IUPAC Information Bulletin, no. 11; also L. F. Fieser \& M. Fieser (1959). The Steroids, chapter 21. New York: Reinhold). The sequence-rule procedure is adopted in these Rules because it gives an unequivocal symbolism.

It is to be noted that, although ring $\mathrm{E}$, like rings $\mathrm{A}$, $\mathrm{B}, \mathrm{C}$ and $\mathrm{D}$, can conveniently be shown by projection on to the plane of the paper, yet ring $F$ cannot be adequately represented in this way since the oxygen atom, C-26, C-24 and C-23 lie in one plane that is perpendicular to the plane of the paper. Ring $F$ is conveniently drawn as in formulae (47)(51); in formula (47), for instance, the broken line from C-22 to oxygen denotes that the oxygen atom and C-26 of ring $\mathrm{F}$ lie behind the plane of the paper and that consequently $\mathrm{C}-23$ and $\mathrm{C}-24$ lie in front of the plane of the paper (configuration $R$ at C-22). In partial formula (48) the configuration at C-22 is reversed and must be stated in the name $(S)$. It is conventional to draw ring $F$ as a chair, but this conformation is not implied in the name 'spirostan'; whatever the conformation of ring F, C-27 and the 25-hydrogen atom both lie in the plane of the paper and so cannot be denoted by broken or thickened lines or designated $\alpha$ or $\beta$. In (47) the methyl group is axial (above the general plane of ring $F$ ), and in (48) it is equatorial (in the general plane of ring $F$ ); in both these cases the configuration at C-25 is $S$, but this identity of $R, S$ designation arises only because the configuration at C-22 has also been reversed between (47) and (48); a $25 R$-configuration is shown in (51). The wavy lines in (49) denote unspecified or unknown configurations at both C-22 and $\mathbf{C - 2 5}$.

The $R, S$ specification may also be affected by substituents attached to ring $\mathrm{F}$ or $\mathrm{C}-27$, as in compounds (A) and (B).
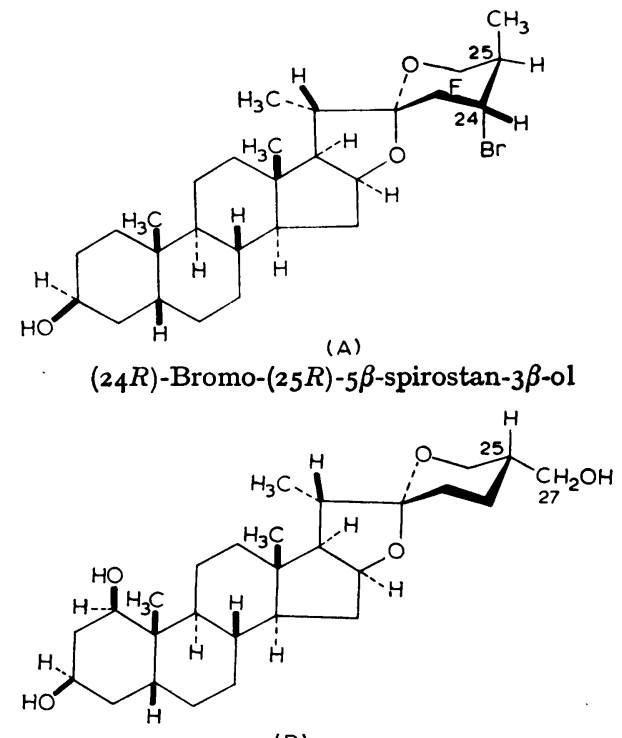

(B)

(25S)-5 $\beta$-Spirostan-1 $\beta, 3 \beta, 27$-triol

3.4. The name 'furostan' is used for the compound of structure (52) (16 $\beta, 22$-epoxycholestane); this name specifies the configurations at all the asymmetric centres except positions 5, 22 and (if position 26 is substituted) also 25. Configuration at C-5 is designated by use of $\alpha$ or $\beta$ in the usual way (see Rule 2S-1.5), and configurations at C-22 and, if necessary, C-25 by the sequence-rule procedure, or in all these cases by $\xi$ if unknown.

Example:

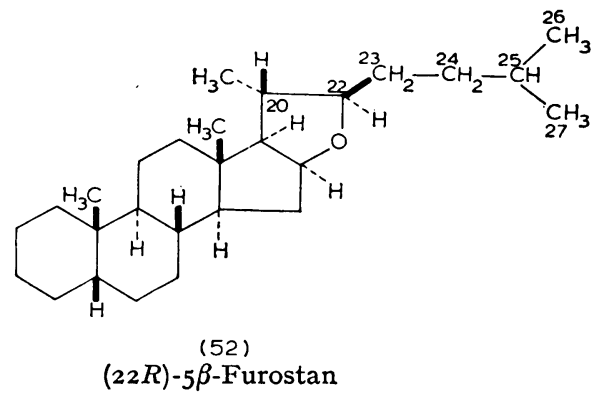

Note: Representative examples of the new standard names and old names (standard names are preferred) for some common types of spirostan, furostan and derived structures are given in the following table and formulae. 
Formula type

47

51

54

55

56

57
(25R)-Spirostan

Standard name

(25S)-Spirostan

$(20 R, 22 S, 25 S)$-Spirostan

$(20 R, 22 R, 25 R)$-Spirostan

$(22 R)$ (or $S$ or $\xi),(25 R)$ (or $S$ or $\xi)$-Furostan

(25R)(or $S$ or $\xi$ )-Furost20(22)-en

Spirostans and furostans

Configurations

implied in

standard name

$20 S, 22 R$

Sapogenin (without prefix)

Neogenin

25-L-Genin

[Sarsasapogenin is (53)]

$20 S, 22 R$

Isogenin

25-D-Genin

[Smilagenin is $(25 R)-5 \beta$-spirostan-3 $\beta$-ol

Tigogenin is $(25 R)$-5 $\alpha$-spirostan- $3 \beta$-ol]

- Cyclopseudoneogenin (54)

- Cyclopseudoisogenin (55)

$20 S$

Dihydrogenin (26-ol) and

Dihydropseudogenin (26-ol)

[Dihydrosarsasapogenin is $5 \beta, 22 \xi, 25 S$-furostan-3 $\beta, 26$-diol Dihydropseudotigogenin is (58); cf. (57)]

Pseudogenin

[Psęudotigogenin is (57)

Pseudosarsasapogenin is (59)

Pseudosmilagenin is (25R)-5 $\beta$-furost-20(22)-en-3 $\beta$,26-diol]

* The standard name is preferred.

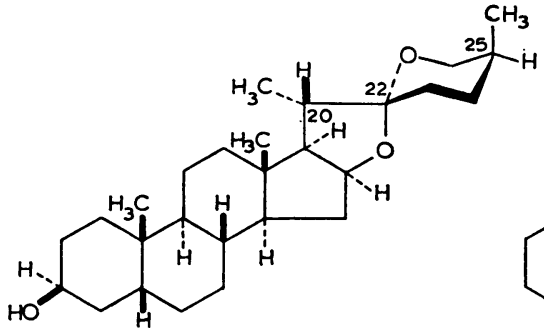

(53)

(25S)-5 $\beta$-Spirostan-3 $\beta$-ol (Sarsasapogenin ${ }^{*}$ )

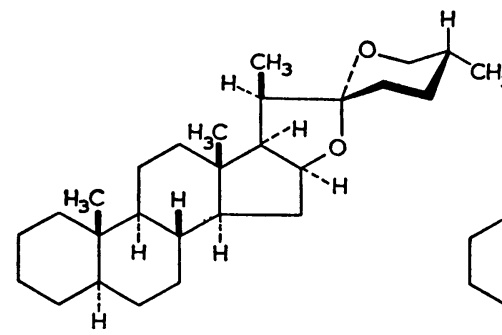

(55)

(20R,22R,25R)-5 $\alpha$-Spirostan (Cyclopseudoisogenin*)<smiles>C[C@@H]1CC[C@@]2(OC1)O[C@H]1C[C@H]3[C@@H]4CC[C@H]5CCCC[C@]5(C)[C@H]4CC[C@]3(C)[C@H]1C2(C)C</smiles>

(54)

(20R,22S,25S)-5 $\beta$-Spirostan (Cyclopseudoneogenin*)

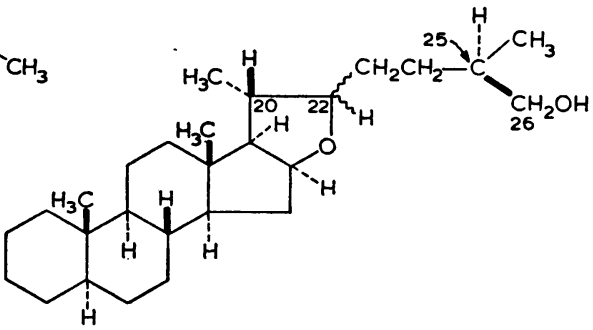

(56)

(20S, 22 $\xi, 25 S)-5 \alpha$-Furostan-26-ol (Dihydrogenin*)

* The standard name is preferred. 


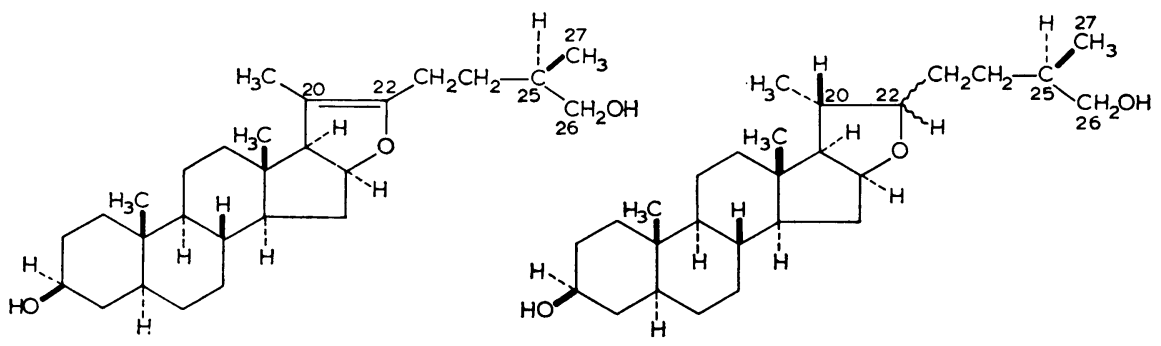

(57)

$(25 R)-5 \alpha$-Furost-2o(22)-en-3 $\beta, 26$-diol (Pseudotigogenin*)
(58)

$(20 S, 22 \xi, 25 R)-5 \alpha$-Furostan-3 $\beta, 26$-diol (Dihydropseudotigogenin*)

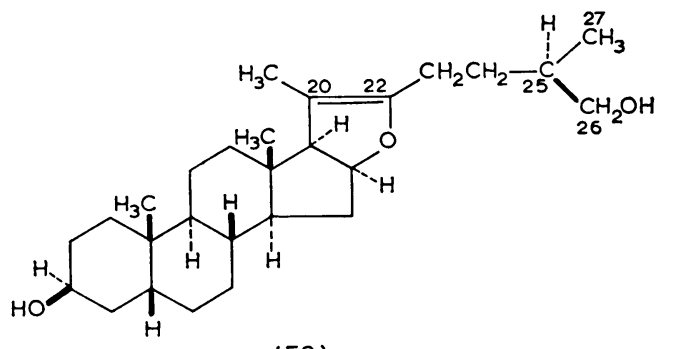

(59)

(25S)-5 $\beta$-Furost-2o(22)-en-3 $\beta$,26-diol (Pseudosarsasapogenin*)

* The standard name is preferred.

\section{Derivatives}

Rule 2S-4 (extended version of Rule S-4).

4.1. Steroid derivatives that can be considered to be formed by modification of, or introduction of substituents into, a parent compound are named by the usual methods of organic chemistry [see IUPAC Nomenclature of Organic Chemistry, Sections $A$ and $B$ (1957), also $J$. Amer. chem. Soc. (1960) 82, 5545-5574, and Section $C$ (1965), London: Butterworths, also Pure appl. Chem. (1965) 11, nos. 1 and 2].

Notes: For the benefit of the specialist, those rules of general substitutive nomenclature that apply most often to steroids are outlined here. For full detail the IUPAC Rules cited above should be consulted.

I. Unsaturation is indicated by changing terminal '-ane' to 'ene', '-adiene', '-yne' etc., or '-an' to '-en', '-adien', '-yn' etc.; e.g. $5 \alpha$-cholest-6-ene, $5 \beta$-cholesta-7,9(11)-diene, 5-spirosten; see also the names of examples (22)-(25). [For uniformity with the IUPAC Rules cited above, the conventions of Chemical Abstracts are used also in the present Rules for the position of locants (positional numerals) and designation of unsaturation. In such matters, and in use of $\Delta$ (Greek capital delta) to designate unsaturation (which is not recommended by IUPAC), authors should respect the house customs of the journals to which their papers are submitted.]
II. Most substituents can be designated either as suffixes or as prefixes; a few can be named only as prefixes, the commonest of these being halogens, alkyl and nitro groups. When possible, one type of substituent must be designated as suffix. When more than one type is present that could be designated as suffix, one type only may be so expressed and the other types must be designated as prefixes. Choice for suffix is made according to an order of preference that is laid down in the Rules cited above; the most important part of this order, for steroids, is as follows, in decreasing preference: 'onium salt, acid, lactone, ester, aldehyde, ketone, alcohol, amine, ether. Suffixes are added to the name of the saturated or unsaturated parent system, the terminal ' $\theta$ ' of '-ane', '-ene', '-yne', '-adiene' etc. being elided before a vowel (presence or absence of numerals has no effect on such elisions). The following examples illustrate the use of these principles.

(a) Acids. Suffix for $-\mathrm{CH}_{3} \rightarrow-\mathrm{COOH}$ : -oic acid Suffix for $\mathrm{CH} \rightarrow \mathrm{C}-\mathrm{COOH}$ : -carboxylic acid

Examples:

11-Oxo-5 $\alpha$-cholan-24-oic acid

(20S)-3 $\alpha$-Hydroxy-5-pregnene-20-carboxylic acid

(b) Lactones, other than cardanolides and bufanolides. The ending '-ic acid' or '-carboxylic acid' of the name of the hydroxy acid is changed to '-lactone' or '-carbolactone' respectively, 
preceded by the locant of the acid group and then the locant of the hydroxyl group, and the prefix 'hydroxy' is omitted for the lactonized hydroxyl group.

\section{Examples:}

$3 \beta$-Hydroxy-5 $\alpha$-cholano- $24,17 \alpha$-lactone

(20R)-3 $\beta$-Hydroxy-5-pregnene-20,18-carbolactone

(c) Cardanolides and bufanolides. The -olide ending of these names denotes the lactone grouping, and substituents must be named as prefixes.

(d) Esters of steroid alcohols. Special procedures are used. For esters of monohydric steroid alcohols, the steroid hydrocarbon radical name is followed by that of the acyloxy group in its anionic form. The steroid radical name is formed by replacing the terminal ' $e$ ' of the hydrocarbon name by ' $y l$ ' and inserting before this the locant and Greek letter, with hyphens, to designate the position and configuration.

Example:

$5 \alpha$-Cholestan- $3 \beta$-yl acetate

For esters of polyols the name of the polyol [cf. (g) below] is followed by that of the acyloxy group(s) in its anionic form, with locants when necessary.

Examples:

$5 \beta$-Cholestane- $3 \alpha, 12 \alpha$-diol diacetate

$5 \beta$-Cholestane-3 $\alpha, 12 \alpha$-diol 3-acetate 12-benzoate

Estradiol-17 $\beta$ 17-monoacetate

When an acid, lactone or spirostan group is also present, the ester group is designated by an acyloxy prefix.

Example:

(25S)-3 $\beta$-Acetoxy-5 $\beta$-spirostan

(e) Aldehydes. Suffixes: -al (denotes change of $-\mathrm{CH}_{3}$ to $-\mathrm{CHO}$, i.e. without change in the number of carbon atoms); -aldehyde (denotes change of $-\mathrm{COOH}$ to $-\mathrm{CHO}$, i.e. without change in the number of carbon atoms; name derived from that of the acid).

Prefix: oxo- (denotes change of $-\mathrm{CH}_{2}$ to $-\mathrm{CO}$, thus also of $-\mathrm{CH}_{3}$ to $-\mathrm{CHO}$, with no change in the number of carbon atoms).

Examples:

$5 \alpha$-Androstan-19-al

$5 \alpha$-Cholan-24-aldehyde

19-Oxo-5 $\alpha, 17(\alpha \mathrm{H})$-etianic acid

Other methods are used for introduction of additional carbon atoms as - $\mathrm{CHO}$ groups. (f) Ketones. Suffix : -one.

Prefix : oxo-.

Examples:

$5 \beta$-Androstan-3-one

5-Pregnene-3,20-dione

11-Oxo-5 $\alpha$-cholan-24-oic acid

(g) Alcohols. Suffix : -ol.

Examples :

Prefix : hydroxy-.

$5 \beta$-Cholestane-3,11-diol

$3 \alpha$-Hydroxy- $5 \alpha$-androstan-17-one

Notes: (1) Composite suffixes -olone and -onol, to denote simultaneous presence of hydroxyl and ketonic groups, are not permitted by IUPAC Rules and should not be used.

(2) A few trivial names exist for hydroxy ketones, such as testosterone for $17 \beta$-hydroxy-4-androsten3-one (see Rule 2S-4.2).

(h) Amines. Suffix : -amine.

\section{Prefix : amino-.}

The suffix may be attached to the name of the parent compound or of its radical.

Examples:

5 -Androsten - $3 \beta$-ylamine or 5 -androsten $-3 \beta$ amine

$3 \beta$-(Dimethylamino)-5 $\alpha$-pregnan-20 $\alpha$-ol

(i) Ethers are named as alkoxy derivatives when another group is present that has priority for citation as suffix.

Examples:

3 $\beta$-Ethoxycholan-24-oic acid

$17 \beta$-Methoxy-4-androsten-3-one

When no such other group is present, ethers of steroid monoalcohols may be named by stating the name of the steroid hydrocarbon radical, followed by the name of the alkyl (or aryl etc.) radical, and lastly by 'ether'; in English these three parts of the name are printed as separate words, for example, $5 \alpha$-androsten- $3 \beta$-yl methyl ether. For ethers of steroid polyols the same system may be used but with the name of the steroid hydrocarbon radical replaced by the name of the polyol; for partially etherified polyols, locant(s) precede the names of the alkyl (or aryl etc.) group(s); for example, $5 \alpha$-pregnane-3 $\beta, 17 \alpha, 20 \alpha$-triol trimethyl ether, $5 \alpha$ pregnane-3 $\beta, 17 \alpha, 20 \alpha$-triol 3,17-dimethyl ether, cortisol 21-methyl ether.

4.2. The following are examples of trivial names retained for important steroid derivatives, these being mostly natural compounds of significant biological activity :
Aldosterone Androsterone Cholecalciferol*
18,11-Hemiacetal of $11 \beta, 21$-dihydroxy-3,20-dioxo-4-pregnen-18-al

$3 \alpha$-Hydroxy-5 $\alpha$-androstan-17-one

9,10 -Seco-5,7,10(19)-cholestatrien-3 $\beta$-ol (for seco see Rule $2 \mathrm{~S}-8$ ) 
Cholesterol

Cholic acid

Corticosterone

Cortisol

Cortisol acetate

Cortisone

Cortisone acetate

Deoxycorticosterone

Ergocalciferol*

Ergosterol

Estradiol-17 $\alpha$

Estradiol-17 $\beta$

Estriol

Estrone

Lanosterol

Lithocholic acid

Progesterone

Testosterone
5-Cholesten-3 $\beta$-ol

$3 \alpha, 7 \alpha, 12 \alpha$-Trihydroxy-5 $\beta$-cholan-24-oic acid

$11 \beta, 21$-Dihydroxy-4-pregnene-3,20-dione

$11 \beta, 17 \alpha, 21$-Trihydroxy-4-pregnene-3,20-dione

Cortisol 21-acetate

$17 \alpha, 21$-Dihydroxy-4-pregnene-3,11,20-trione

Cortisone 21-acetate

21-Hydroxy-4-pregnene-3,20-dione (i.e. the 11-deoxy derivative of corticosterone)

9,10-Seco-5,7,10(19),22-ergostatetraen-3 $\beta$-ol (for seco see Rule 2S-8)

5,7,22-Ergostatrien-3 $\beta$-ol

$1,3,5(10)$-Estratriene-3,17 $\alpha$-diol

$1,3,5(10)$-Estratriene-3,17 $\beta$-diol

$1,3,5(10)$-Estratriene-3,16 $\alpha, 17 \beta$-triol

3-Hydroxy-1,3,5(10)-estratrien-17-one

8,24-Lanostadien-3 $\beta$-ol

$3 \alpha$-Hydroxy-5 $\beta$-cholan-24-oic acid

4-Pregnene-3,20-dione

17 $\beta$-Hydroxy-4-androsten-3-one

* Included in the List of Trivial Names for Miscellaneous Compounds of Biochemical Importance published by the IUPAC-IUB Commission of Biochemical Nomenclature; see, for example, IUPAC Information Bulletin, no. 25, p. 19 (1966), or J. biol. Chem. (1966) 241, 2987 or Biochim. biophys. Acta (1965) 107, 1, or Biochem.J. (1967) 102, 15, or Europ.J. Biochem. (1967) $2,1$.

Note: If these trivial names are used as a basis for naming derivatives or stereoisomers, the derived trivial name must make the nature of the modification completely clear and is preferably accompanied at first mention by the full systematic name. For example, in steroid papers 'epi' is often used with trivial names to denote inversion at one centre; the name '11-epicortisol' defines the compound fully since cortisol is already defined as the $11 \beta$-alcohol; but the name 'epicortisol' does not define the compound and is inadequate.

4.3. Androstane-17-carboxylic acids may be called 'etianic acids', although the former (systematic) name is preferred. The orientation of the hydrogen atoms at positions 5 and 17 must in all cases be indicated as $5 \alpha$ or $5 \beta$, and $17(\alpha \mathrm{H})$ or $17(\beta \mathrm{H})$, respectively.

Examples:

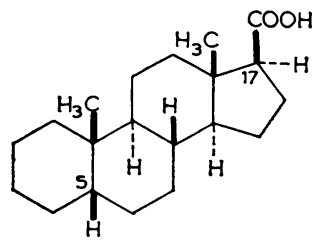

(60)

$5 \beta$-Androstane- $>7 \beta$-carboxylic acid (systematic) or $5 \beta, 17(\alpha \mathrm{H})$-etianic acid (trivial)<smiles>C[C@]12CCCC[C@H]1CC[C@@H]1[C@@H]2CC[C@H]1C(=O)O</smiles>

(61)

$5 \alpha$-Androstane-1 $7 \beta$-carboxylic acid (systematic) or $5 \alpha, \mathrm{I} 7(\alpha \mathrm{H})$-etianic acid (trivial)

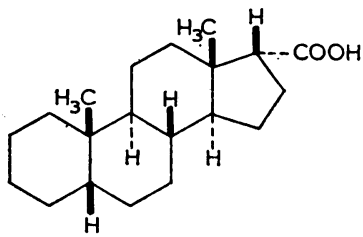

(62)

$5 \beta$-Androstane-I $7 \alpha$-carboxylic acid (systematic) or $5 \beta, 17(\beta \mathrm{H})$-etianic acid (trivial)

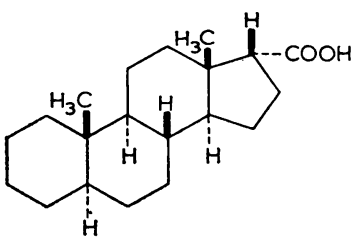

(63)

$5 \alpha$-Androstane-1 $7 \alpha$-carboxylic acid (systematic) or $5 \alpha, 17(\beta \mathrm{H})$-etianic-acid (trivial) 


\section{Stereochemical modifications}

Rule 2S-5 (extended version of Rule S-5).

5.1. If, as for instance in a synthetic compound, there is stereochemical inversion at all the asymmetric centres whose configurations do not require to be specified in a name, the italicized prefix ent(a contracted form of enantio-) is placed in front of the complete name of the compound. This prefix denotes inversion at all asymmetric centres (including those due to named substituents) whether these are cited separately or are implied in the name.

Examples:<smiles>CC12CCC(=O)C=C1CCC1C2CCC2(C)C1CC[C@H]2O</smiles>

(64)

I 7 -Hydroxy-4-androsten-3-one (Testosterone)<smiles>CC12CCC(=O)C=C1CCC1C2CCC2(C)C(O)CCC12</smiles>

(65)

ent-1 $7 \beta$-Hydroxy-4-androsten-3-one (ent-Testosterone)

Note: When Roman or Arabic numerals are used to enumerate formulae, the prefix ent may be used to indicate the enantiomer. Thus, e.g., (65) above may be designated (ent-64).

5.2. If there is stereochemical inversion at a minority of the asymmetric centres whose configurations do not require to be specified in a name, the configuration of the hydrogen atoms or substituents at the affected bridgeheads, or the carbon chain (if any) at position 17, are stated by means of a prefix or prefixes $\alpha$ or $\beta$, each with its appropriate positional numeral, placed before the stem name laid down in the preceding Rules.

Examples:<smiles>CO[C@H]1CC[C@H]2[C@@H]3CC[C@H]4CC(=O)CC[C@]4(C)[C@H]3CC[C@]12C</smiles>

(66)

$5 \beta, 9 \beta$, Io $\alpha$-Pregnane-3,20-dione

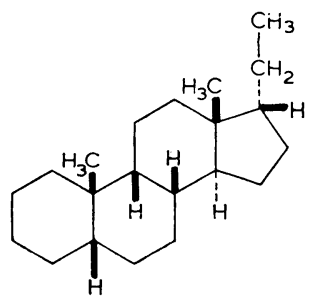

(67)

$5 \beta, 9 \beta$, I $7 \alpha$-Pregnane

5.3. The enantiomer of a compound designated as in Rule 5.2 is given the same name preceded by ent-.

Note: This Rule covers the compounds in which there is inversion at a majority, but not all, of the asymmetric centres that do not require to be specified in the name.

Examples:

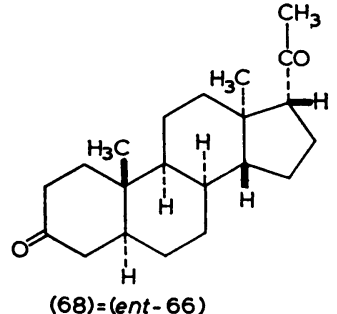

ent-5 $\beta, 9 \beta$, 10 $\alpha$-Pregnane-3,20-dione

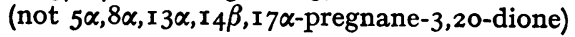

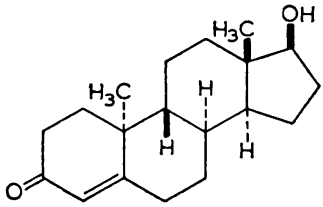

(69)

ent-1 $7 \alpha$-Hydroxy-1 $3 \alpha, \mathrm{I} 4 \beta$-androst-4-en-3-one (not I7 $\beta$-hydroxy-8 $\alpha, 9 \beta$, Io $\alpha$-androst-4-en-3-one)

5.4. If there is stereochemical inversion at half of the asymmetric centres whose configurations are implied in the stem name of a 'normal' steroid [e.g. (70)], the prefixes to be specified in the name of the stereoisomer are that set that includes the number occurring first in the series $8,9,10,13$, 14,17 without or with the prefix ent-as appropriate. 
(70) 'Normal' steroid

(71) Steroid inverted at 8 and 10 ; 'normal' at 9 and 13

(72) (ent-71) Steroid inverted at 9 and 13 ;

'normal' at 8 and 10

\author{
Configuration \\ at asymmetric \\ centres
}

Name

$8 \beta, 9 \alpha, 10 \beta, 13 \beta \quad 5,14-$ Androstadiene

$8 \alpha, 9 \alpha, 10 \alpha, 13 \beta \quad 8 \alpha, 10 \alpha$-Androsta-5,14-diene

$8 \beta, 9 \beta, 10 \beta, 13 \alpha \quad$ ent-8 $\alpha, 10 \alpha$-Androsta-5,14-diene
Note: (72) could also logically be named ' $9 \beta, 13 \alpha$ androsta-5,14-diene'; this name might seem simpler, but it has the disadvantage that it does not indicate that (72) is the enantiomer of (71).

5.5. Racemates, as for instance obtained by synthesis, are named by use of an italicized prefix rac- (an abbreviation of racemo-), placed before the complete name of the compound, the enantiomer chosen for naming being that required by Rules 2S-5.1 to 2 S-5.4.

Example: A racemate composed of (64) and (65) (=ent-64) is named:

rac-17 $\beta$-Hydroxy-4-androsten-3-one or rac-testosterone

5.6. (a) When the relative, but not the absolute, configuration of two or more asymmetric centres in a steroid derivative is known, as for instance for a compound obtained by synthesis, the $10 \beta$-configuration is taken as basis for the name; or, if C-10 is not asymmetric or is absent, the lowest-numbered asymmetric bridgehead is designated $\alpha$ (or $R$ ); the other asymmetric centres are then considered as $\alpha$ or $\beta$ (or $R$ or $S$ ) relative to that one; and the whole name is prefixed by rel- (italicized). Individual asymmetric centres may be referred to as $\alpha^{*}, \beta^{*}$, $R^{*}$ or $S^{*}$ (spoken as alpha star, $\mathrm{R}$ star etc.) but these symbols are not used in the name of the compound.

(b) When both enantiomers of known relative, but unknown absolute, configuration are prepared, they are distinguished by a prefix $(+)$-rel- or (-)-rel-, where the plus or minus sign refers to the direction of rotation of plane-polarized light (the wavelength, solvent, temperature and/or concentration must be added when known to affect this sign).<smiles>C[C@]12CCC(=O)C=C1CC[C@@H]1[C@@H]2CC[C@@]2(C)[C@H](O)CC[C@H]12</smiles>

(73)

The dextrorotatory form having either this or the enantiomeric configuration would be named: (+)-rel-17 $\beta$-Hydroxy-8 $\alpha ; 9 \beta$-androst-4-en-3-one<smiles>CCOC(=O)[C@H]1CC[C@H]2C(CCO)=C3C=CC4=CC=C[C@H]4[C@H]3[C@@H]12</smiles>

(74 A)<smiles>CCOC(=O)C1(C(=O)OCC)CC[C@@H]2C(=C1CCO)C=CC1=CC=C[C@@H]12</smiles>

(74A) rel-(Ethyl 2-hydroxy-2,3-seco- $A$-nor-5 $\alpha$-gona-9, I I, I 3(1 7), I 5-tetraen-3-oate) (for seco see Rule $2 \mathrm{~S}-8$ and for nor see Rule $2 \mathrm{~S}-7$ ) or $(74 \mathrm{~B}) \mathrm{rel}$ - $[(7 R, 9 \mathrm{a} S, 9 \mathrm{bS})$-Ethyl $8,9,9 \mathrm{a}, 9 \mathrm{~b}$-tetrahydro- $7 H$-cyclopenta $[a]$ naphthalene-7-carboxylate] 
Note: At some stage in synthetic work on steroids, names of intermediates have to be changed from a system used in general organic chemistry to the steroid system. The names (74A) and (74B) illustrate such a change and it should be noted (i) that not merely the name but also the numbering are usually changed and (ii) that the steroid name usually avoids the need to specify the configuration at each asymmetric centre. The latter factor will often indicate at what point in a synthesis the change of nomenclature is desirable.

\section{Shortening of side chains and elimination of methyl groups}

Rule 2S-6 (expanded from Rule S-6).

6.1. Elimination of a methylene group from a steroid side chain (including a methyl group) is indicated by the prefix 'nor-', which in all cases is preceded by the number of the carbon atom that disappears. When alternatives are possible, the number attached to nor is the highest permissible. Elimination of two methylene groups is indicated by the prefix 'dinor-'.

Examples:<smiles>CCC(C)[C@H]1CC[C@H]2[C@@H]3CC[C@H]4CCCC[C@]4(C)[C@H]3CC[C@@]21C</smiles>

(75)

24-Nor-5 $\beta$-cholane<smiles>CC(=O)[C@H]1CC[C@@H]2[C@@H]1CC[C@H]1[C@H]2CCC2=CC(=O)CC[C@@]21C</smiles>

(76)

28-Nor-4-pregnene-3,20-dione

Exceptions: By Rules 2S-2.1 and 2S-2.2 the names gonane (for 18,19-dinorandrostane) and estrane (for 19-norandrostane) constitute exceptions to the above Rule 2S-6.1. The names gonane and estrane are used also as parent names for their derivatives.

However, 18-nor- and 19-nor- are used with other trivial names, as in 19-norpregnane, 18,19-dinorspirostan, 18-norestrone.
The compound produced by shortening the 17-side chain of pregnane is named 17-methylandrostane rather than 21-norpregnane. See also Note to Rule 2S-2.2.

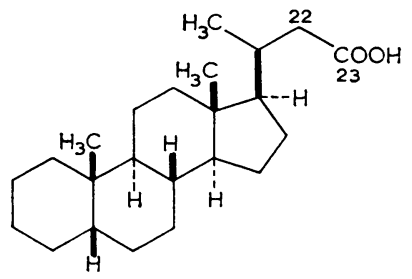

(77)

24-Nor-5 $\beta$-cholan-23-oic acid<smiles>CC(C(=O)O)[C@H]1CC[C@@H]2[C@@H]1CC[C@@H]1[C@@H]3CCCC[C@H]3CC[C@@H]21</smiles>

(77a)

I8, 19-Dinor-5 $\alpha$-pregnane-20 $\alpha$-carboxylic acid

Ring contraction or expansion

Rule 2S-7 (amended version of Rule S-7).

7.1. Ring contraction and ring expansion (other than insertion of atoms between directly linked bridgeheads or, when a steroid side chain is present, between C-13 and C-17) are indicated by prefixes 'nor' and 'homo' respectively, preceded by an italic letter indicating the ring affected. For loss or insertion of two methylene groups, 'dinor' and 'dihomo' are used. 'Homo' and 'nor', when occurring in the same name, are cited in alphabetical order. (Alphabetical order is used for any combination of cyclo, homo, nor and seco; they are placed immediately before the stem name and after any prefixes denoting substituents.)

Examples:

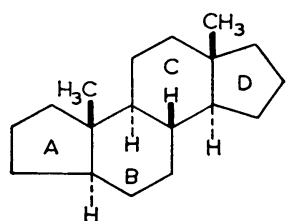

(78)

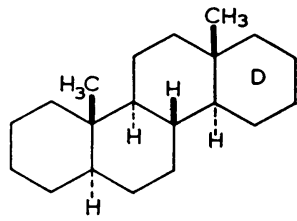

(79)
$A$-Nor-5 $\alpha$-androstane 


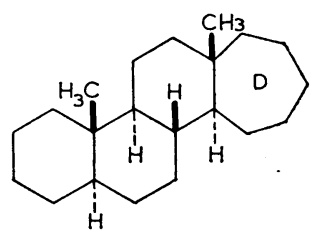

(80)

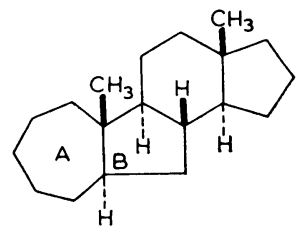

(81)
$D$-Dihomo-5 $\alpha$-androstane $A$-Homo- $B$-nor- $5 \alpha$-androstane

Notes: (a) By too extended use, this nomenclature can be applied to compounds whose steroid character is excessively modified. It is recommended that it be confined to steroids containing at least one angular methyl group, or a steroid 17-side chain, or a steroidal group on ring $D$ (e.g. a spirostan); also that no more than two of the steroid rings may be altered by any combination of the operations denoted by 'nor' and 'homo'. When these conditions are not met, general systematic nomenclature should be used.

(b) Names incorporating 'homo' and 'nor' are normally preferred to alternatives incorporating 'cyclo' and 'seco' [cf. example (86)].

7.2. On ring contraction the original steroid numbering is retained, and only the highest number(s) of the contracted ring, exclusive of ring junctions, is deleted.

Example:<smiles>CC1(C)CCC2C3CC[C@]4(C)CCCC4C3CCC21C</smiles>

$A$-Nor- $5 \alpha$-androstane (Number 4 is omitted)

7.3. On ring expansion (other than insertion of atoms between directly linked bridgeheads or, when a 17-side chain is present, between C-13 and C-17), the letter $a$ (and $b$ etc. as necessary) is added to the highest number in the ring enlarged exclusive of ring junctions, and this letter and number are assigned to the last peripheral carbon atom in the order of numbering of the ring affected.

Examples:

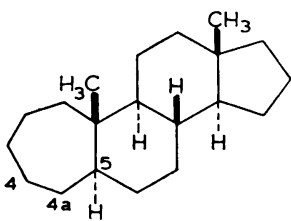

(83)

$A$-Homo- $5 \alpha$-androstane

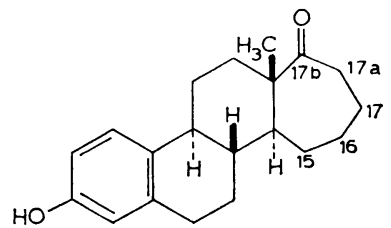

(84)

3-Hydroxy- $D$-dihomo-r, 3,5(ro)-estratrienI $7 \mathrm{~b}$-one

7.4. Ring expansion by formal insertion of a methylene group between directly linked bridgeheads is indicated as shown in the annexed table. The italic capital letters denote the ring(s) affected; the locants in parentheses (which are included in the name) are those of the inserted methylene groups.

\begin{tabular}{cl}
$\mathrm{CH}_{2}$ added between & \multicolumn{1}{c}{ Prefix used } \\
C-5 and C-10 & $A B(10 a)$-Homo \\
C-8 and C-9 & $B C(8 a)$-Homo \\
C-8 and C-14 & $C(14 a)$-Homo \\
C-9 and C-10 & $B(9 a)$-Homo \\
C-13 and C-14 & $C D(13 a)$-Homo
\end{tabular}

Examples:

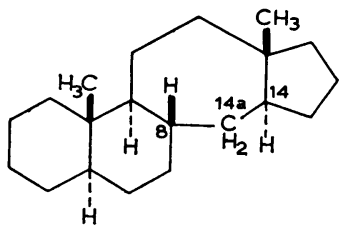

(85)

$C(14 a)$-Homo- $5 \alpha$-androstane

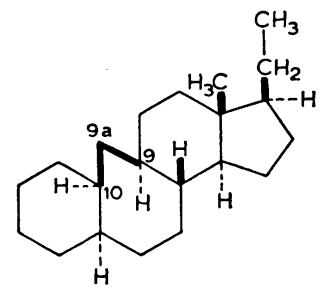

(86)

$B(9 a)$-Homo-r9-nor $-5 \alpha, \operatorname{ro} \alpha(\mathrm{H})$-pregnane*

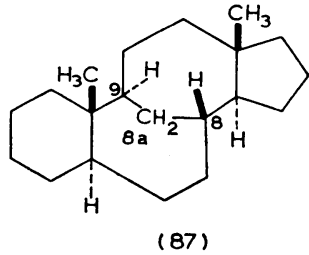

$B C(8 a)$-Homo- $5 \alpha$-androstane

* This name is preferred to $9 \beta, 19$-cyclo-9,10-seco$5 \alpha, 10(\alpha \mathrm{H})$-pregnane (see Note b to Rule 2S-7.1). This skeleton is contained in some Buxus alkaloids. 
7.5. Expansion of ring $D$ by insertion of atoms between C-13 and C-17: The names ' $D$-homopregnane', ' $D$-homocholane' etc. are used only for the isomer with the side chain at position 17a [cf. example (88)]. Isomers with the side chain at position 17 (formed by formal insertion of a methylene group between C-13 and C-17) are named as derivatives of androstane, estrane or gonane [cf. example (89)]. As exceptions, furostans and spirostans into which a methylene group has been formally inserted between $\mathrm{C}-13$ and $\mathrm{C}-17$ are given these names with an added prefix ' $D(17 a)$-homo' [cf. example (90)].

Examples:<smiles>CC[C@H]1CCC[C@H]2[C@H]3CC[C@H]4CCCC[C@]4(C)[C@H]3CC[C@]12C</smiles>

(88)

$D$-Homo-5 $\alpha$-pregnane

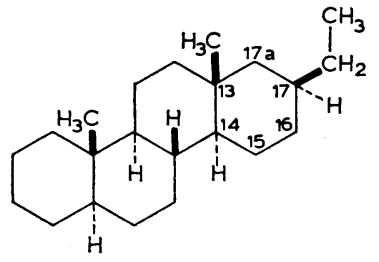

(89)

I $7 \beta$-Ethyl- $D$-homo-5 $\alpha$-androstane

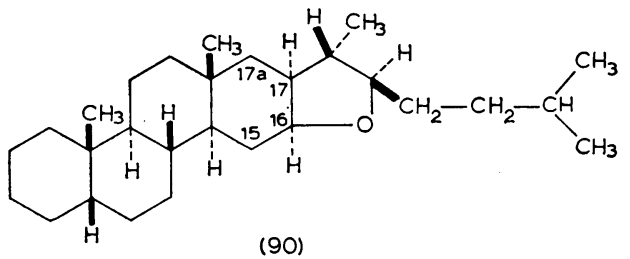

(22R)-D(I7a)-Homo-5 $\beta$-furostan

\section{Ring fission}

Rule 2S-8 (unchanged from Rule S-7.4).

8.1. Fission of a ring, with addition of a hydrogen atom at each terminal group thus created, is indicated by the prefix 'seco-', the original steroid numbering being retained. (If more than one ring is opened, general systematic nomenclature may be preferable. The principles of Note a to Rule 2S-7.1 apply also to seco-steroids.)

Examples:

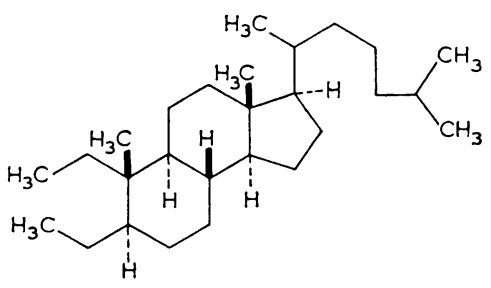

(91)

2,3-Seco- $5 \alpha$-cholestane<smiles>CC(C)CCCC(C)[C@H]1CCC2C3CC[C@H](CC(=O)O)C(C)(CC(=O)O)C3CCC21C</smiles>

(92)

2,3-Seco-5 $\alpha$-cholestane-2,3-dioic acid<smiles>CC1(C(=O)O)CCC2c3ccc(O)cc3CCC2C1CC(=O)O</smiles>

(93)

3-Hydroxy-16, 1 7-seco-I, 3,5(10)-estratrieneI6, 17-dioic acid<smiles>C=C1CCC(O)C/C1=C/C=C1/CCC[C@]2(C)C(C(C)CCCC(C)C)CC[C@@H]12</smiles>

(94)

9, I0-Seco-5,7, Io(I9)-cholestatrien-3 $\beta$-ol (trivial name: cholecalciferol*)

* This trivial name is retained (see Rule 2S-4.2).

\section{Modification by bond migration (abeo system)}

Rule 2S-9 (new).

9.1. A compound that does not possess a steroid skeleton but may be considered formally to arise from a steroid by bond migration may be given the name laid down in the preceding Rules for the steroid in question, to which is attached a prefix of the form $x(y \rightarrow z)$ abeo-. This prefix is compiled as follows: A numeral denoting the stationary (unchanged) end of the migrating bond $(x)$ is followed by parentheses enclosing (i) the number denoting the original position $(y)$ from which the 
other end of this bond has migrated, (ii) an arrow, and (iii) the number $(z)$ denoting the new position to which the bond has moved. The closing parenthesis is followed by abeo- (Latin, I go away) (italicized) to indicate bond migration. The original steroid numbering is retained for the new compound and is used for the numbers $x, y$ and $z$. Such of the customary letters as are necessary are added to specify the resulting stereochemistry.

Note: The abeo nomenclature described in this Rule is permissive, not compulsory. It is most suitable for use in discussions of reaction mechanism and biogenesis. For registration in a general (non-steroid) compendium the general systematic names may be preferable, particularly when names of steroid type can be conveniently assigned by the homo-nor method. Differences in numbering between abeo names and other systematic names should be particularly noted [cf. example (96)].

Examples:

\section{Hetero modifications}

Rule 2S-10 (unchanged from Rule S-7.5).

10.1. If hetero atoms occur in the ring system of a steroid the replacement ('oxa-aza') system of nomenclature is used with steroid names and numbering (cf. IUPAC Rule B-4 ; also Introduction to IUPAC Rules C-0.6; references are those given in 2S-4.1).

Example:<smiles>C[C@]12CC[C@@H]3[C@H](CC=C4OC(=O)CC[C@@H]43)[C@@]1(C)CC[C@@H]2O</smiles>

(99)

I7 $\beta$-Hydroxy-4-oxa-5-androsten-3-one

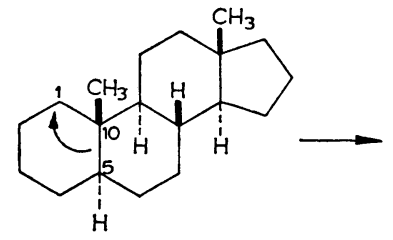

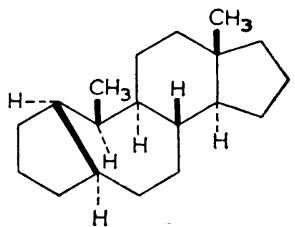

(95)

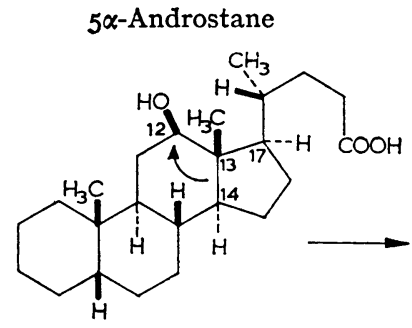

I $\beta$-Hydroxy-5 $\beta$-cholan-24-oic acid

$5(\mathrm{Io} \rightarrow \mathrm{I} \alpha \mathrm{H})$ abeo- $5 \alpha$-Androstane*<smiles>C[C@H](CCC(=O)O)[PH+]1CC[C@H]2[C@@H]3CC[C@H]4CCCC[C@]4(C)[C@H]3C[C@H]2[C@H]1C</smiles>

(96) $\mathrm{I}_{4}\left(\mathrm{I}_{3} \rightarrow \mathrm{I} 2 \beta \mathrm{H}\right)$ abeo-5 $\beta$-Chol-r3(I7)-en-24-oic acid $\dagger$

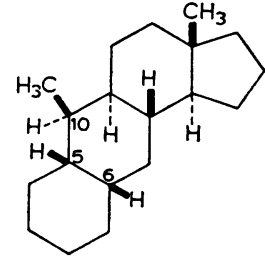

(98)

(97) $\mathrm{I}_{4}(8 \rightarrow 9 \xi) a b e o-5 \alpha$-Cholestane $\ddagger \quad \mathrm{I}(\mathrm{Io} \rightarrow 6 \beta \mathrm{H})$ abeo-5 $\beta$-Androstane (an anthrasteroid)

$5 \alpha$-Cholestane

* Name according to Rule 2S-7.4: 9a $\beta$-Methyl-B(9a)-homo- $A$-nor-5 $\alpha, 10 \alpha$-estrane.

$\dagger$ Name according to Rules $2 S-2.4$ and $2 S-8.1$ : $12 \alpha, 14 \beta$-Cyclo-13,14-seco-5 $\beta$-chol-13(17)-en-24-oic acid.

$\ddagger$ The configuration at C.9, if known, is assigned by the sequence-rule procedure (see references cited in the Introduction). 


\section{Steroid alkaloids}

Rule 2S-11 (new).

11.1. When readily possible, systematic names for steroid alkaloids are derived from pregnane or some other steroid parent name. Trivial names for other steroid alkaloids are chosen so that the name for the saturated system ends in '-anine'. In names for unsaturated compounds this ending is changed to '-enine', '-adienine' etc., as appropriate. When asymmetry exists at positions 8,9 , $10,13,14,16,17,20$ or 23 , it is implied in the name, as set out in the annexed table and formulae, and divergences are designated as laid down in Rule $2 \mathrm{~S}-5$. Configurations at positions 5,22 , and 25 must be specified with the name. Sequence-rule symbols are used for positions numbered 20 or higher.

Examples: Typical examples of parent names for groups of alkaloids are given in the annexed table and the corresponding formulae. It must be noted that substitution or unsaturation may alter the $R, S$ designations for derivatives.
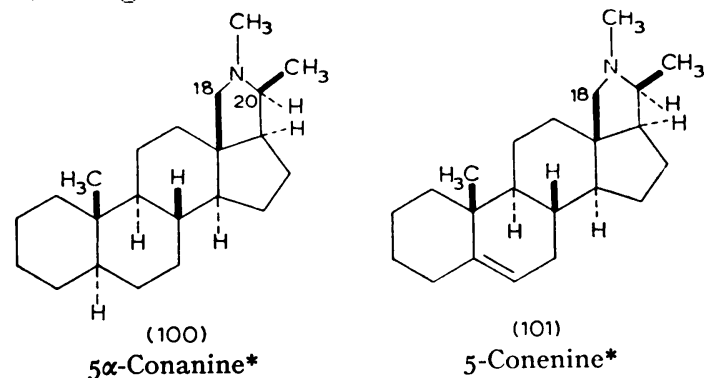

$5 \alpha$-Conanine*

5-Conenine*

* Cf. R. D. Haworth \& M. Michael (1957). J. chem. Soc. p. 4973.
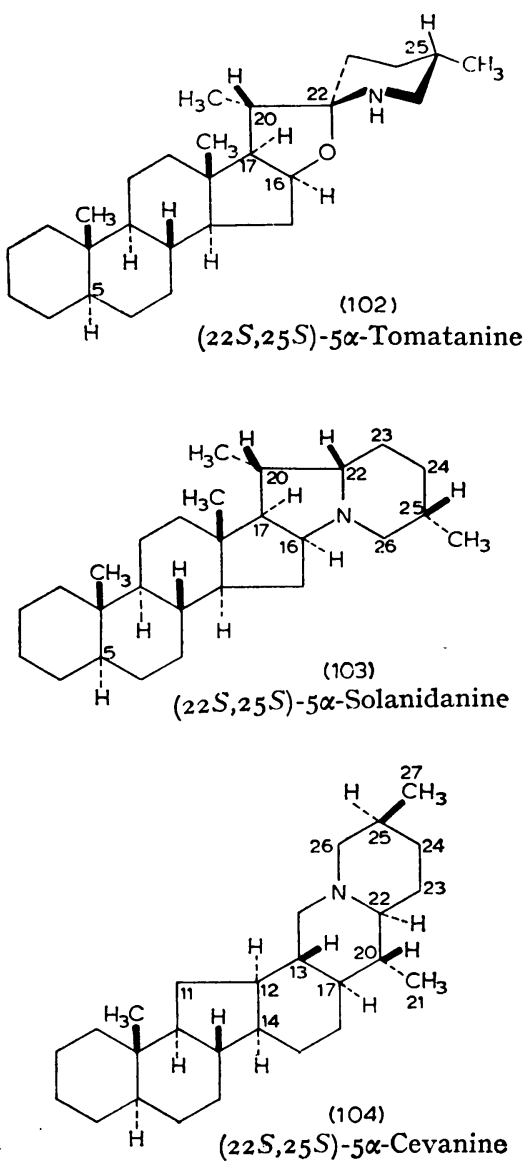

Parent names for groups of steroid alkaloids ${ }^{a}$

$\begin{array}{cccc}\text { Formula } & \text { Name of parent } & \begin{array}{c}\text { Stereochemistryb implied } \\ \text { in the name, as shown } \\ \text { in the formula }\end{array} & \begin{array}{c}\text { Stereochemistry to be } \\ \text { indicated by } \\ \text { sequence-rule prefixes }\end{array} \\ (100) & \text { Conanine } & 17 \alpha \mathrm{H}, 20 S & \text { (or } \xi) \\ (102) & \text { Tomatanine }^{c} & 16 \alpha \mathrm{H}, 17 \alpha \mathrm{H}, 20 S & - \\ (103) & \text { Solanidanine }^{d} & 16 \alpha \mathrm{H}, 17 \alpha \mathrm{H}, 20 S & 22,25 \\ (104) & \text { Cevanine }^{e} & 17 \alpha \mathrm{H}, 13 \beta \mathrm{H}, 20 R & 22,25 \\ (105) & \text { Veratranine, }^{e} & 17 \alpha \mathrm{H}, 20 S & 22,25 \\ (106) & \text { Jervanine }^{e} f & 17 \alpha 0,20 R & 22,25 \\ & & & 22,23,25\end{array}$

$a$ Some of the names in this table were suggested in the Introduction to Optical Rotatory Power, 1a, Steroids, Tables des Constantes (1965), pp. 2a and 2f, Oxford: Pergamon Press.

$b$ Additional to that at positions 8, 9, 10,13 and 14 .

$c$ The compounds are oxa-aza analogues of the spirostans (which are dioxa spiro compounds). Formulae are conveniently drawn analogously to those of the spirostans.

${ }^{d}$ This group includes rubijervine and isorubijervine.

- These structures contain a $D$-homo- $C$-nor skeleton, with the stereochemistry shown. However, they are commonly considered as $14(13 \rightarrow 12)$ abeo structures and are numbered as such.

$f$ Jervanine, as defined here, is the same as veratranine except for addition of an epoxy bridge, but it is convenient to have two separate names: the veratranine skeleton (see 105) is present in the alkaloid veratramine. It should be noted that the name $5 \alpha$-jervane has been used for the rearranged hydrocarbon skeleton (107) [J. Fried \& A. Klingsberg (1953). J. Amer. chem. Soc. 75, 4934], for which the abeo-type numbering given in (107) is here recommended. 


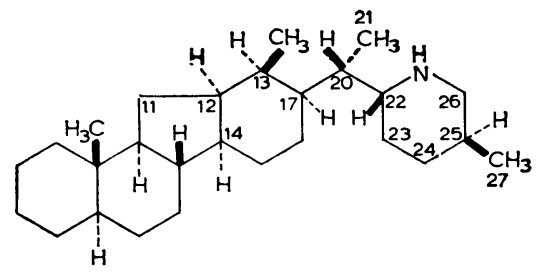

(105)

$(22 R, 25 S)-5 \alpha$-Veratranine

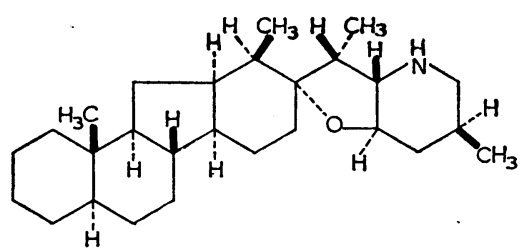

(106)

$(22 S, 23 R, 25 S)-5 \alpha$-Jervanine

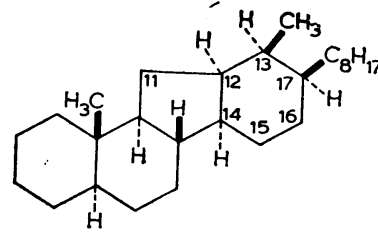

(107)

$5 \alpha$-Jervane*

* Cf. J. Fried \& A. Klingsberg (1953). J. Amer. chem. Soc. 75, 4934.

\section{APPENDIX}

Guide lines for steroids containing additional rings

1. General. When additional rings are formed within, or on, a steroid nucleus, situations often arise where either the resemblance to a normal steroid is obscured or the steroid-type name becomes so complex that recourse to general systematic nomenclature is preferable. On the other hand, the general rules, with one exception, are based on that form of each component that contains the maximum number of conjugated double bonds, the whole fused system is then renumbered, and the stereochemistry must be defined separately for each chiral position; the final name resulting is then cumbrous and in a form that is often barely recognizable by a steroid specialist chemist and even less so by a biochemist or biologist. The paragraphs below give suggestions as to how general nomenclature may be modified to incorporate steroid names, but without any attempt to legislate rigidly or to cover every case. The decision whether any one compound shall receive such a modified steroid name or a general systematic name is left to authors and editors in the particular circumstances of each case. Nor are the requirements of journals and compendia or abstracts necessarily identical.

2. Rings derived from functional groups. Bivalent functional groups such as $-\mathrm{O}$ - and $-\mathrm{O}-\mathrm{O}$ - linked to two different positions, thus forming additional rings, are named by the ordinary methods of organic chemistry; for example, (108) is $3 \alpha, 9$-epidioxy-5 $\alpha$-androstan-17-one. Similarly, methylenedioxy derivatives are best named as such, e.g.

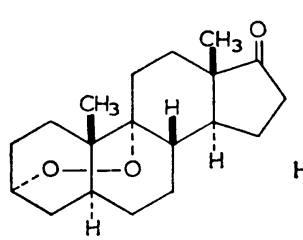

(108)

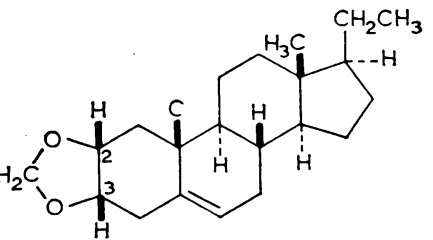

(109)
(109) $2 \alpha, 3 \alpha$-methylenedioxy-5-pregnene. In the same way, lactones and acetals formed by linkage between two different positions of a steroid skeleton are best named as such instead of framing the name on the newly modified ring system.

3. Additional carbocyclic or heterocyclic fused rings. It is tempting to adapt the simple substitutive procedure for fusion of steroid nuclei with simple carbocyclic rings, particularly if the latter are saturated. Thus (110) might be named $2 \alpha, 3 \beta$ tetramethylene-5 $\alpha$-androstane. (For simplicity, nomenclature in this Appendix is mostly described in terms of androstane, and partial formulae are to be understood accordingly. The principles, however, are general.) However, formation of additional<smiles>C[C@]12C[C@@H]3CCCC[C@@H]3C[C@@H]1CC[C@H]1[C@@H]2CC[C@@]2(C)CCC[C@@H]12</smiles><smiles>C[C@]12Cc3ccccc3C[C@@H]1CC[C@@H]1[C@@H]2C[C@@]2(C)CCC[C@@H]12</smiles>

(111)

rings by alkylene $\left(-\left[\mathrm{CH}_{2}\right]_{x^{-}}\right)$prefixes is not in accord with IUPAC nomenclature and is often difficult to apply when unsaturation is present. Alternatives are thus preferable.

The exceptional case (Rule A-23.5) referred to above enables 2,3-benz-5 $\alpha$-androst-2-ene to be a name for (111), and a slight extension of the rule would allow (110) to be called $2 \beta, 3 \alpha$-cyclohexano$5 \alpha$-androstane. Such methods might be used in simple cases but these too become difficult when complex ring systems are fused and often when unsaturation is present in the additional component. 
For a general procedure it is better to modify systematic IUPAC general practice to permit the steroid component to be cited in a reduced state, the reason why modification is necessary at all being of course the wish to keep the description of the stereochemistry as simple as possible. The suggestions below are closely similar to present practices of Chemical Abstracts.

An additional carbocyclic component is cited in its most unsaturated form by its fusion name (usually ending in -o), placed in front of the name of the steroid component, and the position of fusion is indicated by numerals in square brackets; for instance, benz[2,3]-5 $\alpha$-androst-2-ene for (111). Here note that the unsaturation of the benzo ring causes unsaturation also in the steroid component and this must be cited (-2-ene). Similarly, (112) is naphtha $\left[2^{\prime}, 3^{\prime}: 2,3\right]-5 \alpha$-androst-2-ene; the steroid $A$ ring is still considered unsaturated even though it<smiles>CC12Cc3cc4ccccc4c(c3C1)C[C@H]1CCCC2(C)C1</smiles>

(112)

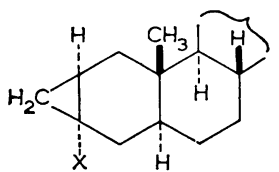

(113)

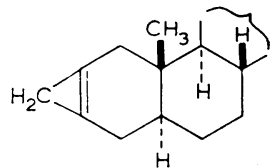

(114) may be preferred to write the naphthalene double bonds as in the formula shown; note also that the locants for the non-steroid component receive primes, and that, when choice is possible, its locants for ring fusion are as low as possible and in the same direction as in the steroid component (i.e. not $6^{\prime}, 7^{\prime}: 2,3$ or $3^{\prime}, 2^{\prime}: 2,3$ ).

The reduced compound (110) is then $2 \beta, 3 \alpha, 3^{\prime}, 4^{\prime}$,$5^{\prime}, 6^{\prime}$-hexahydrobenz[2,3]-5 $\alpha$-androstane. Note the citation of the configuration at the new ringjunction positions and that the steroid component is now cited in its saturated state.

Two further points can be illustrated with (113). Consider first the hydrocarbon where $X=H$. The additional ring is cited as cyclopropa, denoting an unsaturated three-membered ring as in (114). In (114) the position of the 'extra' (indicated) hydrogen must be cited as $2^{\prime} H$. Reduction of (114) to $(113 ; \mathrm{X}=\mathrm{H})$ adds $2 \alpha, 3 \alpha$-dihydro to the name, which thus becomes $2 \alpha, 3 \alpha$-dihydro-2' $H$-cyclopropa$[2,3]-5 \alpha$-androstane. If $X$ were not hydrogen but, say, $\mathrm{OH}$, the hydro prefixes would still be needed to show the state of hydrogenation and the $\mathrm{OH}$ group would be named additionally; in such cases it is preferable to state the configuration for the $\mathrm{OH}$ group that is present rather than that of the $\mathrm{H}$ atom that has been replaced; the name then becomes $2 \alpha, 3$ - dihydro - $2^{\prime} H$ - cyclopropa[2,3] - $5 \alpha$ - androstan $3 \alpha$-ol.

The same fundamental principle can be used for heterocyclic components, but conveniently modified to accord with general nomenclature as follows: (a) the heterocyclic component is cited after the steroid component (to permit modification of the ending for salt formation etc.), and (b) the position of fusion of the heterocyclic component is cited by letters as in the standard IUPAC and Ring Index method. Thus (115) is $2^{\prime}$-methyl-2'H-5 $\alpha$-androst2-eno[3,2-c]pyrazole; note the numbering of the pyrazole ring so that numbers for ring fusion are as low as possible; if the methyl group in (115) were

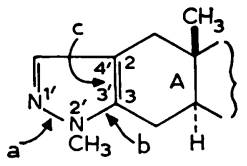

(115)

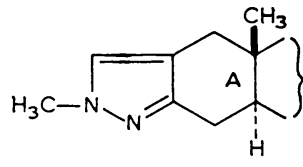

(116) replaced by hydrogen, the double bonds would be placed in the mesomeric pyrazole ring just as in (115) so as to retain this low numbering for ring fusion. In the isomer (116) the steroid component is no longer unsaturated and is therefore cited as androstano-; the full name for (116) is $1^{\prime}$-methyl$1^{\prime} H-5 \alpha$-androstano[3,2-c]pyrazole.

Further problems arise when ring fusion involves a quaternary carbon atom. The name for (117), for instance, could be built up as follows: to $5 \alpha$ pregnane is fused an isoxazole skeleton, giving (118);

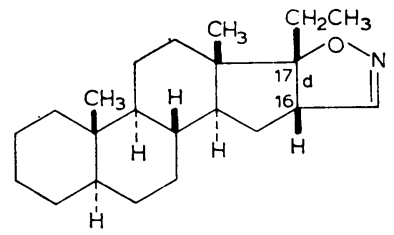

(117)

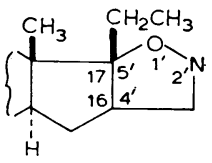

(118)

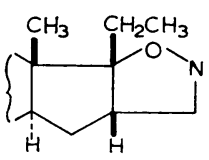

(119) into this, only one double bond can be introduced, so that one hydrogen atom must be added as indicated hydrogen, which gives a $4^{\prime} \beta H$ - prefix and a skeleton (119). The last step, inserting the double bond, gives the full name $4^{\prime} \beta H$-5 $\alpha$-pregnano$[16,17-d]$ isoxazole, even though it appears in (117) 
as if the heterocyclic ring should be named as the partly hydrogenated system isoxazoline.

Not all such fusions cause all these complications.

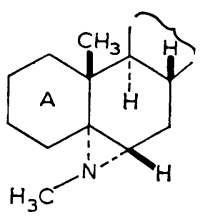

(120)

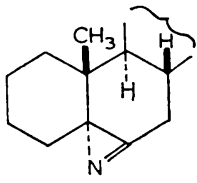

(121)
For instance, for (120) one fuses androstane to azirine, obtaining a skeleton into which one inserts a double bond as in the hypothetical compound (121); then, clearly, (120) is $1^{\prime}, 3^{\prime}$-dihydro-1'. methyl-5 $\alpha$-androstano[5,6-b]azirine.

4. Stereochemistry. Stereochemistry in additional rings that lie in the approximate plane of rings $A-D$ is cited as $\alpha$ or $\beta$, but in other cases by means of sequence-rule symbols.

5. Spiro derivatives. Spiro derivatives of steroids are named in accordance with the principles laid down in IUPAC Rules A-41, A-42, B-10 and B-11. Additional stereochemistry due to the spiro junction and substituents in the non-steroid ring is designated by the sequence-rule procedure. Alternative names permitted by IUPAC Rules are illustrated for (122) and (123).

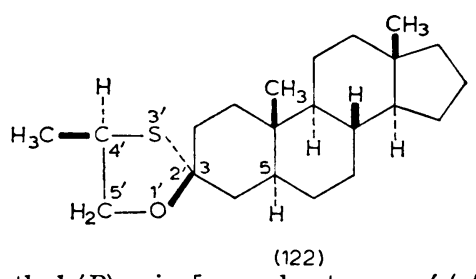

$4^{\prime} R$-Methyl-(R)-spiro[ $5 \alpha$-androstane- $3,2^{\prime}-\left(\mathrm{r}^{\prime}, 3^{\prime}\right.$-oxathiolane $\left.)\right]$

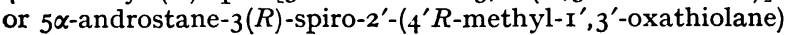

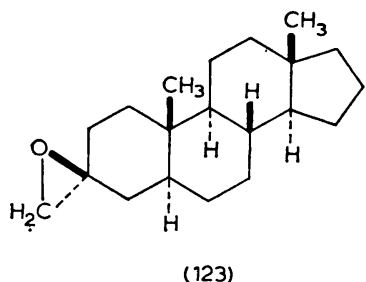

(3S)-Spiro[5 $\alpha$-androstane-3,2'-oxiran] or $(3 S)$ - $5 \alpha$-androstane-3-spiro-2'-oxiran

Acknowledgement. We are indebted to Elsevier Publishing Company for permission to reproduce photographically the chemical structures that appeared in their publication of these Tentative Rules in Biochimica et Biophysica Acta.

All Tentative Rules of the IUPAC-IUB Commission on Biochemical Nomenclature (CBN) as well as a Document for Discussion are available from Waldo E. Cohn, Director, NAS-NRC Office of Biochemical Nomenclature, Oak Ridge National Laboratory, P.O. Box Y, Oak Ridge, Tenn. 37830, U.S.A.:

Abbreviations and Symbols for Chemical Names of Interest in Biological Chemistry. Revised Tentative Rules [see Biochem.J. (1966) 101, 1].

Nomenclature of Vitamins, Coenzymes and Related Compounds: Trivial Names of Miscellaneous Compounds of Importance in Biochemistry, Nomenclature of Quinones with Isoprenoid Side Chains, Nomenclature and Symbols for Folic Acid and Related Compounds, Nomenclature of Corrinoids. Tentative Rules [see Biochem. J. (1967) 102, 15].

Abbreviated Designation of Amino Acid Derivatives and Peptides. Tentative Rules [see Biochem. J. (1967) 102, 23].

Rules for Naming Synthetic Modifications of Natural Peptides. Tentative Rules [see Biochem.J. (1967) 104, 17].

The Nomenclature of Lipids. A Document for Discussion [see Biochem. J. (1967) 105, 897].

Abbreviated Nomenclature of Synthetic Polypeptides (Polymerized Amino Acids) [see Biochem. J. (1968) 106, 577].

The Nomenclature of Cyclitols. Tentative Rules [see Biochem. J. (1969) 112, 17]. A One-Letter Notation for Amino Acid Sequences. Tentative Rules [see Biochem. $J$. (1969) 113, 1].

Revised Tentative Rules for Nomenclature of Steroids [this document]. 
A document, OBN-5, describing the (American) NAS-NRC Office of Biochemical Nomenclature, and listing other rules affecting biochemical nomenclature, is available from its Director, Dr Waldo E. Cohn [see also J. chem. Docum. (1967) 7, 72]. 